\title{
NMR spectroscopy in wine authentication: An official control perspective
}

\author{
Pavel A. Solovyev ${ }^{1}$ (c) ～ Carsten Fauhl-Hassek $^{2} \quad \mid$ Janet Riedl $^{2} \quad \mid$ Susanne Esslinger $^{2}$ \\ Luana Bontempo ${ }^{1}$ (1) | Federica Camin ${ }^{1,3}$ (이
}

${ }^{1}$ Department of Food Quality and Nutrition, Research and Innovation Center, Fondazione Edmund Mach (FEM), via E. Mach 1, San Michele all'Adige 38010, Italy

${ }^{2}$ German Federal Institute for Risk Assessment, Department Safety in the Food Chain, Unit Product Identity, Supply Chains and Traceability, Max-Dohrn Strasse, 8-10, Berlin 10589, Germany ${ }^{3}$ Center Agriculture Food Environment (C3A), University of Trento, via Mach 1, San Michele all'Adige, Tennessee, 38010, Italy

\section{Correspondence}

Federica Camin, Center Agriculture Food Environment(C3A), University of Trento, via Mach 1, 38010 San Michele all'Adige (TN), Italy.

Funding information Program of the Autonomous Province of Trento (Italy) with EU co-financing (Fruitomics), Grant/Award Number: FESR 2014-2020

\begin{abstract}
Wine authentication is vital in identifying malpractice and fraud, and various physical and chemical analytical techniques have been employed for this purpose. Besides wet chemistry, these include chromatography, isotopic ratio mass spectrometry, optical spectroscopy, and nuclear magnetic resonance (NMR) spectroscopy, which have been applied in recent years in combination with chemometric approaches. For many years, ${ }^{2} \mathrm{H}$ NMR spectroscopy was the method of choice and achieved official recognition in the detection of sugar addition to grape products. Recently, ${ }^{1} \mathrm{H}$ NMR spectroscopy, a simpler and faster method (in terms of sample preparation), has gathered more and more attention in wine analysis, even if it still lacks official recognition. This technique makes targeted quantitative determination of wine ingredients and nontargeted detection of the metabolomic fingerprint of a wine sample possible. This review summarizes the possibilities and limitations of ${ }^{1} \mathrm{H}$ NMR spectroscopy in analytical wine authentication, by reviewing its applications as reported in the literature. Examples of commercial and open-source solutions combining NMR spectroscopy and chemometrics are also examined herein, together with its opportunities of becoming an official method.
\end{abstract}

\section{KEYWORDS}

food analysis, food fraud, metabolomics, nuclear magnetic resonance (NMR), wine

\section{1 | INTRODUCTION}

Wine is a very important food commodity in Europe. In 2018, the production of wine in the European Union (EU) member countries reached 181.9 million hectoliters (International Organization of Vine and Wine, 2019b). That accounted for over $60 \%$ of the world wine production that year and made a contribution of over $€ 7$ billion to the EU trade balance (European Commission Directorate-General for Agriculture and Rural Development, 2019); and the world figures of wine trade reached $€ 31$ billion by 2018
(International Organization of Vine and Wine, 2017, 2019a) (see Figure 1).

Markets with such enormous production volumes and values are often plagued by fraudulent practices. It may be stated that wine fraud is one of the oldest and most common cases of adulteration in the food industry (Everstine, Spink, \& Kennedy, 2013; Holmberg, 2010), through the use of diverse malpractice techniques, starting from the simple addition of chemicals to improve the characteristics of wine (the most known case is probably the diethylene glycol wine scandal in 1985; Brüders, 1999), up 

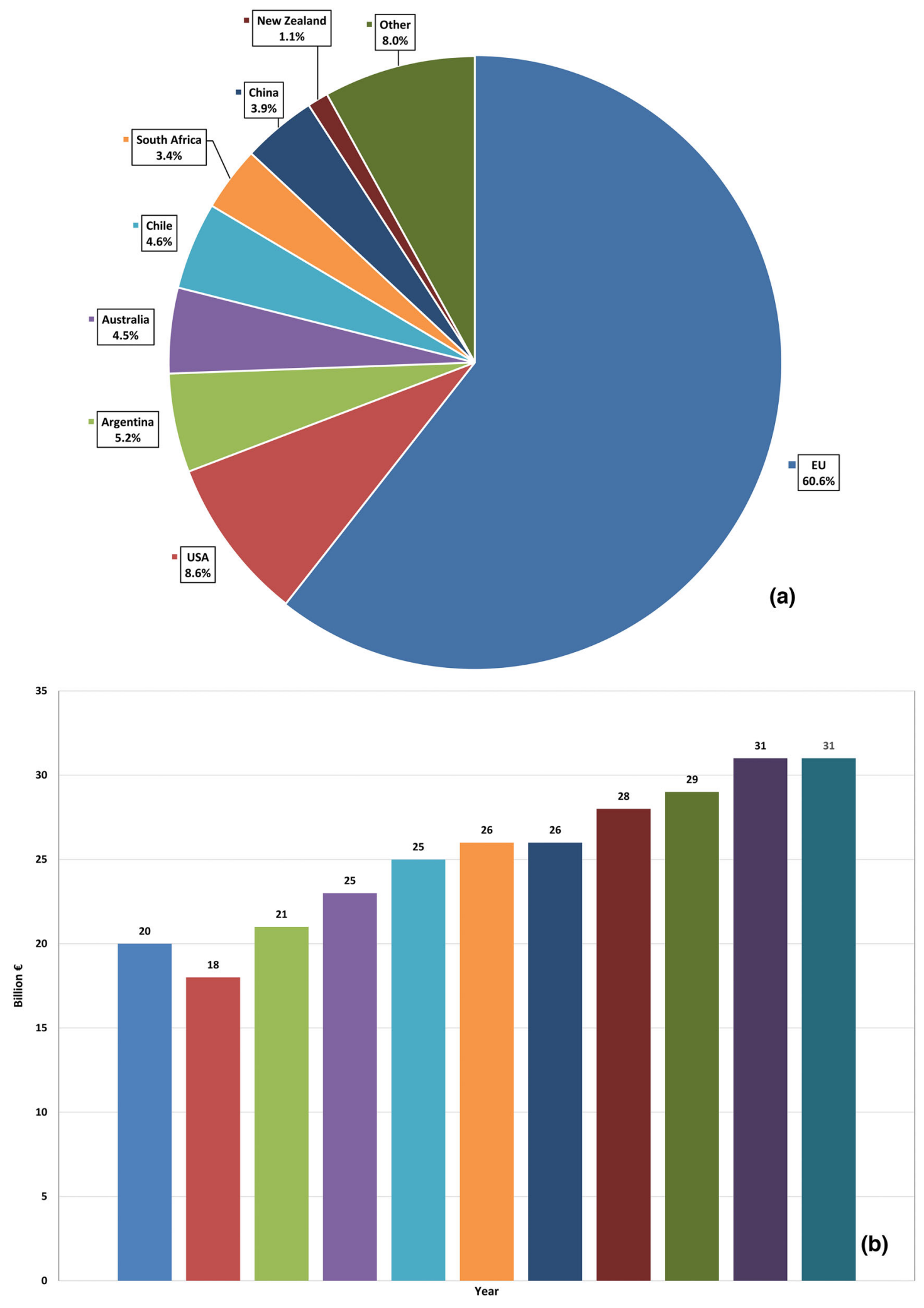

F I G U R E 1 a. 2018 world wine production data (European Commission Directorate-General for Agriculture and Rural Development, 2019)

FIGURE $1 \mathrm{~b}$ 2008-2018 world wine export data (International Organization of Vine and Wine, 2017, 2019a) 
to the dilution/replacement of expensive wine types with cheaper ones or mislabeling (such as the case with fake Tuscany Brunello wines in 2008; Cavicchi \& Santini, 2011) and many others. Wine as an alcoholic beverage always scores in the top ten list of the most often adulterated commodities (European Commission, 2019; Moore, Spink, \& Lipp, 2012). Indeed, wine adulteration is currently on the rise in Europe: according to the latest report of the EU Intellectual Property Office (EUIPO), the value of counterfeit goods in this area amounts to $€ 50$ billion, with spirits and wine accounting for $€ 2.3$ billion thereof ( $5.3 \%$ of direct lost sales), with a consequent total employment loss of 31,858 jobs (European Union Intellectual Property Office, 2020). In 2019, over a dozen serious cases were reported by law authorities in the EU acting against wine fraud (European Commission's Science and Knowledge Service, 2018, 2019a, 2019b, 2019c, 2019d, 2019e, 2019f, 2019g), and approximately the same number in 2020 (European Commission's Science and Knowledge Service, 2020a, 2020b, 2020c, 2020d). In the USA, only the criminal activity of Rudy Kurniawan, who by 2006 sold counterfeit collection wines for the total sum of $\$ 35$ million, has inflicted so much uncertainty to the auction market, that in several years after his arrest in 2012 the average prices dropped 25 to $30 \%$, though this did not significantly affect the retail market (Fougere, Kaplan, \& Collins, 2020). In the UK, the Treasury estimates that the cost of alcohol fraud accounts for approximately $£ 1.3$ billion of revenue loss each year (Wine and Spirit Trade Association, 2015). It is alleged that in China wine fraud is so widespread that as much as $30 \%$ of all alcohol (Shen, 2018) or $50 \%$ of wine that costs over $\$ 35$ is actually counterfeit (Muhammad \& Countryman, 2019).

Therefore, in order to control such malpractices effectively, it is necessary to use robust and reliable analytical methods, both physical and chemical. For many decades the classical methods of wine authentication have been wet chemistry, for the determination of the total and volatile acid content or the enzymatic analysis of sugars, and instrumental analysis by high-performance liquid chromatography (HPLC) and gas chromatography (GC) coupled with detection methods such as mass spectrometry (HPLC-MS or GC-MS), for the quantification of wine components or by-products (Arvanitoyannis, 2010; MeierAugenstein, 1999; Montet \& Ray, 2017). More recently, the combination of different methodologies with chemometrics has become increasingly popular in wine authentication, including, for instance, infrared (IR), ultraviolet and visible (UV/VIS) spectroscopy (Ricci, Parpiniello, Laghi, Lambri, \& Versari, 2013), isotopic (Camin et al., 2017) and biochemical (Medina et al., 2013) methods including nuclear magnetic resonance (NMR) spectroscopy (Fan et al., 2018).
NMR spectroscopy also has a long tradition in wine authentication. For many years, the site-specific natural isotopic fractionation NMR (SNIF NMR) spectroscopy developed by Martin and colleagues in the late 1980s (Martin \& Martin, 1981; Martin, Martin, Mabon, \& Michon, 1983, 1988) has been the golden standard for the determination of nonauthorized chaptalization. In fact, SNIF NMR spectroscopy is the only analytical method that can determine the addition of beet sugar prior to fermentation. This quantitative method relies on the nonstatistic distribution of deuterium in the starting sugar and its reflection in the resulting ethanol after fermentation. The relation of the $\mathrm{D} / \mathrm{H}$ isotope ratio in the methylic and methylenic sites of ethanol determined by ${ }^{2} \mathrm{H}$ NMR spectroscopy verifies the botanical origin of ethyl alcohol in wine (Martin, Martin, Mabon, \& Michon, 1982).

Nowadays, another NMR spectroscopic approach based on proton $\left({ }^{1} \mathrm{H}\right)$ measurement is becoming popular in wine analysis. In contrast to deuterium analysis by SNIF NMR spectroscopy, proton measurement is the classical application of NMR spectroscopy in organic chemistry, which is typically used for structure elucidation. In relation to wine, it was applied for the identification, as well as quantification, of its components (wine metabolites). This started over 40 years ago (Anders, Tittgemeier, \& Hailer, 1976), with the analysis of ethanol content. With technological improvements, such as the increase in electronics sensitivity, the possibility of obtaining precise temperature control and the enhanced phase and baseline correction, this technique could be applied to the highly reproducible determination of minor organic components (see Amargianitaki \& Spyros, 2017; Fotakis, Kokkotou, Zoumpoulakis, \& Zervou, 2013, for reviews). With these technical improvements, ${ }^{1} \mathrm{H}$ NMR spectroscopy makes targeted quantitative determination of substances in wine (quantitative NMR/qNMR spectroscopy) (López-Rituerto et al., 2009; Remaud, Silvestre, \& Akoka, 2005) possible. Furthermore, it is possible to use the entire ${ }^{1} \mathrm{H}$ NMR spectrum for analysis, interpreting it as a unique fingerprint of the wine sample and predicting wine properties by classification models (nontargeted approach) (Godelmann et al., 2013).

One of the main manufacturers of NMR spectroscopic equipment, Bruker Biospin Corporation (Billerica, MA, USA), commercially adopted the targeted and nontargeted approach for the analysis of biological fluids, such as liquid foods (Belton et al., 1996; Gil et al., 2004), in particular, fruit juices (Belton et al., 1998; Belton et al., 1997; Spraul et al., 2008). This resulted in the creation of an NMR spectroscopy-based automated tool for fruit juice quality control, based on a $400 \mathrm{MHz}$ device. The system (called "SGF Profiling"; Humpfer et al., 2009; Spraul et al., 2009) combines both targeted and nontargeted NMR spectroscopy for decentralized measurements according to a 
harmonized protocol and centralized data evaluation on a Bruker server (single parameter and properties verification), for a price. After refinement, the Bruker company reported validation results for this product, available on the market as "JuiceScreener" since 2009 (Monakhova et al., 2014; Spraul et al., 2009; Spraul, Schütz, Humpfer, et al., 2009). This technology was extended to other food sectors (Spraul et al., 2009) and Bruker released the "WineScreener" or "Wine Profiling" system (Hofmann, 2015) as well as the NMR "Honey-Profiling."

Apart from this commercial and well-recognized proprietary solution, many studies have demonstrated the applicability of ${ }^{1} \mathrm{H}$ NMR spectroscopy to wine authentication, mainly in feasibility studies, but its introduction for official controls has not yet been completed (S. Esslinger, FauhlHassek, \& Wittkowski, 2015; Esslinger, Riedl, \& FauhlHassek, 2014; Riedl, Esslinger, \& Fauhl-Hassek, 2015). Therefore, the aim of this review is to discuss the applications of NMR spectroscopy to wine authentication as well as the obstacles to their implementation in official controls.

\section{2 | STATUS QUO}

\subsection{Site-specific natural isotope fractionation (SNIF) NMR spectroscopy}

SNIF NMR spectroscopy is based on the acquisition of a ${ }^{2} \mathrm{H}$ spectrum. Due to the low natural frequency of deuterium, ${ }^{2} \mathrm{H}$ NMR spectroscopic measurement is not a conventional application of NMR spectroscopy, unlike proton measurement or ${ }^{13} \mathrm{C}$ NMR spectroscopic analysis. The gyromagnetic ratio of deuterium is about 6.5 times smaller than for protons $\left({ }^{1} \mathrm{H}\right)$, and the measurement sensitivity is therefore significantly reduced. When using a $400 \mathrm{MHz}$ NMR spectrometer, the measuring time for an alcohol sample is at least 3 hours. Furthermore, a special probe head optimized for deuterium acquisition is required for the measurement.

The intramolecular distribution of deuterium is neither statistical nor random, but closely related to the origin and synthesis of the substance of interest. Based on the signal intensities of deuterium in the various positions in the molecule and on the relevant standard, it is possible to calculate the $\mathrm{D} / \mathrm{H}$ ratios for each specific position. The most prominent application of SNIF NMR spectroscopy is the ${ }^{2} \mathrm{H}$ NMR spectroscopic analysis of wine alcohol, particularly with regard to the detection of beet sugar illegally added to must prior to fermentation. The sample preparation in this case entails the distillation of the wine sample using a specific apparatus, a spinning band fractionation column (Baker, Barkenbus, \& Roswell, 1940; Glenn, 1963; Mayo et al., 1988), sometimes called Cadiot column (Cadiot et al., 2004), in order to exceed a distillation yield of $96 \%$ (International Organization of Vine and Wine, 2019c) to avoid isotopic fractionation. In the case of wine must or grape juice, it has to be fermented to complete exhaustion of sugar prior to distillation using said device.

${ }^{2} \mathrm{H}$ NMR spectroscopic analysis has been used successfully for decades in wine authentication official controls (Christoph, Hermann, \& Wachter, 2015). After adaptation as an official method, a joint isotopic data bank of authentic wine from all wine-producing EU member states was established. Its purpose is to "ensure more effective control of wine product enrichment" and "help to verify conformity with the origin indicated in their name" (European Commission, 1991a, 1991b, 2000, 2008). The database especially allows the comparison of dubious samples with authentic data and thereby improved control of chaptalization and water addition. Besides the $\mathrm{D} / \mathrm{H}$ ratios obtained by SNIF NMR, isotopic ratio mass spectrometry (IRMS)retrieved parameters, such as the ${ }^{13} \mathrm{C} /{ }^{12} \mathrm{C}$ ratio in ethanol and the ${ }^{18} \mathrm{O} /{ }^{16} \mathrm{O}$ ratio in wine water have been included in the database. The SNIF NMR spectroscopic method is thereby stipulated by official wine control regulations and has been approved for its suitability in legal cases (Camin et al., 2017).

\section{2 | ${ }^{1} \mathrm{H}$ NMR spectroscopy}

For wine authentication, ${ }^{1} \mathrm{H}$ NMR spectroscopy shows some advantages in comparison with ${ }^{2} \mathrm{H}$ NMR spectroscopy-although one has to keep in mind that the two methods consider different pieces of information, compositional versus isotopic. With respect to data acquisition, ${ }^{1} \mathrm{H}$ NMR spectroscopy is very fast because of the high natural abundance of ${ }^{1} \mathrm{H}$ isotope (99.9885 wt.\%) (Holden, Coplen, \& Böhlke, 2018; Meija et al., 2016). Hence, measuring takes only a few minutes (usually $<15 \mathrm{~min}$ ), and the number of scans commonly used here ranges from 8 to 64 (Ralli et al., 2018). Furthermore, ${ }^{1} \mathrm{H}$ NMR spectroscopy is now highly reproducible and has a wide linearity range. It makes the quantification of a wide range of metabolites in parallel, as well as the pattern analysis (prediction of target properties), possible, using the same spectrum. Thus, only one measurement is necessary to receive multiple responses (to qualitative as well as quantitative issues). Moreover, NMR spectroscopic measurements are nondestructive (Arapitsas \& Mattivi, 2018; S. E. Ebeler, 2015; Flamini, 2008; Zoecklein, Fugelsang, Gump, \& Nury, 1999). In general, NMR spectrometers are very robust and, compared with other systems, e.g., mass spectrometers, almost free of maintenance.

There are also some disadvantages in using ${ }^{1} \mathrm{H}$ NMR spectroscopy for wine authentication. This method has 
lower sensitivity compared with other techniques such as mass spectrometry, by approximately several nanomoles when cryoprobes are used (Pan \& Raftery, 2007), or by over a micromole without them, whereas MS is 10 to 100 times more sensitive (Emwas, 2015; Emwas et al., 2019).

Moreover, most of the organic compounds give complex signals due to spin-spin coupling, resulting in several peaks per single component and overlaid peaks from various components. This makes data interpretation particularly challenging (Pinu, 2018).

The analysis of wine by ${ }^{1} \mathrm{H}$ NMR spectroscopy can be performed with targeted and nontargeted approaches. In terms of sample preparation, both strategies require a simple but unspecific procedure and a low sample volume (typically $0.6 \mathrm{ml}$ ). The literature mainly describes two preparation procedures: (a) direct analysis or (b) freeze drying (lyophilization) of the sample to remove water and ethanol, so that their large signals do not overlap those of minor components or otherwise affect them (Hu et al., 2015; Zhu, Hu, Lu, \& Xu, 2018). For specific purposes, such as the analysis of phenolic compounds, specific extraction steps might be necessary to avoid interferences. Wine must was also freeze-dried, and freeze drying was used or extraction with various solvents (Fotakis et al., 2013) has been used for the analysis of grapes.

Regardless of how the samples were prepared, the addition of a deuterated solvent (such as $\mathrm{D}_{2} \mathrm{O}, \mathrm{MeOD}$, or a mixture of the two), for the deuterium lock signal, and the addition of an internal standard for spectrum reference are necessary. The reference standards of the chemical shift scale in ppm that are commonly used for aqueous samples in NMR spectroscopy are formic acid (or its derivatives), 3-trimethylsilylpropionic acid (TSP) or 2,2-dimethyl-2-silapenthane-5-sulfonate (DSS) (Spyros \& Dais, 2012).

As the $\mathrm{pH}$ value affects the chemical shift of certain signals, related to acids, it is advisable to adjust the $\mathrm{pH}$ of the wine samples to a precise value (to the second decimal point) in order to minimize the intersample variation of the signal positions. The $\mathrm{pH}$ value of wine typically varies between 2.8 and 3.4 (Jackson, 2014; Moreno-Arribas \& Polo, 2009), sometimes this range is being cited as wider, for example 2.9 to 4.2 (Robinson \& Harding, 2015) or 3.0 to 3.7 (Waterhouse, Sacks, \& Jeffery, 2016) and wine itself must be considered as a buffer system, due to its high content in minerals and acids. Mathematical algorithms have also been described as an alternative to physical $\mathrm{pH}$ adjustment of samples, for example, ICOSHIFT (intervalcorrelation-shifting) (Savorani, Tomasi, \& Engelsen, 2010) alone, or in combination with IFFD (fluctuation frequency difference) algorithm (Wang, Barding, \& Larive, 2015).

Due to the composition of wine, when direct analysis is performed, its ${ }^{1} \mathrm{H}$ NMR spectrum shows a predominance of the water signal ( $\sim 4.8 \mathrm{ppm}$ ), followed by the ethanol signals, the quartet of the methylene group at $3.6 \mathrm{ppm}$ and the triplet of the methyl group at $1.2 \mathrm{ppm}$, whereas further signals are not visible at first glance in a simple ${ }^{1} \mathrm{H}$ NMR spectrum (see Figure 2).

Multiple signal suppression, in which the water, ethanol methylene, and methyl group signals are suppressed eightfold, was introduced by Monakhova et al. (2011). This results in significant signal enhancement of the minor components. The distortion of the spectrum sections, close to the suppressed areas, remains minimal, thus signals very close to the suppressed range can be evaluated and quantified as well (see Figure 3).

Wine is a complex mixture of several hundred organic compounds of various classes (Jackson, 2014; Waterhouse et al., 2016). Many of these were successfully identified using ${ }^{1} \mathrm{H}$ NMR spectroscopy, such as amino acids (Kosir \& Kidric, 2001), alcohols (Nilsson et al., 2004), sugars (Castillo-Muñoz et al., 2008), carboxylic acids and their derivatives (Baderschneider \& Winterhalter, 2001), phenolic compounds (Vitrac et al., 2005), and carbonyl compounds such as aldehydes and ketones (Pinto et al., 2018). The search for novel metabolites is never over, however; and studies on this topic emerge constantly. For example, nitrogen-containing glycoconjugate 3-indolyl-(2R)-O$\beta$-D-glucosyl-lactic acid was recently found in bordeaux red wine, with the specific aim to use it as a tag (Fabre et al., 2014). Glutathione, both reduced (GSH) and oxidized (GSSG), is another example; here, these compounds were identified by totally correlated 2D NMR spectroscopy (TOCSY) (Kontogianni, Tsiafoulis, Roussis, \& Gerothanassis, 2017). New carboxylic acids, such as oleanic and xanthurenic acids were also discovered in Italian wines (Forino, Gambuti, \& Moio, 2019). Isolation and characterization of dextran (exopolysaccharide) generated by certain species of bacteria during the production of Chinese homemade wine (Du et al., 2018, 2019) is a more specific case and may possibly serve as an origin marker. New substances have been isolated not only from wine itself, but also from its precursors, for example, grapes: such is the case of flavan-3-ol monohexosides (Zerbib et al., 2018) and epicatechin-3-O-vanillate (Ma, WaffoTéguo, Jourdes, Li, \& Teissedre, 2018), polyphenols (for review, see Radovanović, Radovanović, \& Arsić, 2018; Ye, Wang, \& Xu, 2015), as well as carbohydrate derivatives (Cretin, Waffo-Teguo, Dubourdieu, \& Marchal, 2019).

Other substances that may be present in wine are introduced by wine production procedures, and these have been studied and characterized using NMR spectroscopy as well. For example, compounds such as quercoresinosides (bitter lignans) (Sindt, Gammacurta, Waffo-Teguo, Dubourdieu, \& Marchal, 2016) or triterpenoids (Gammacurta et al., 2019) are released into the wine by the 


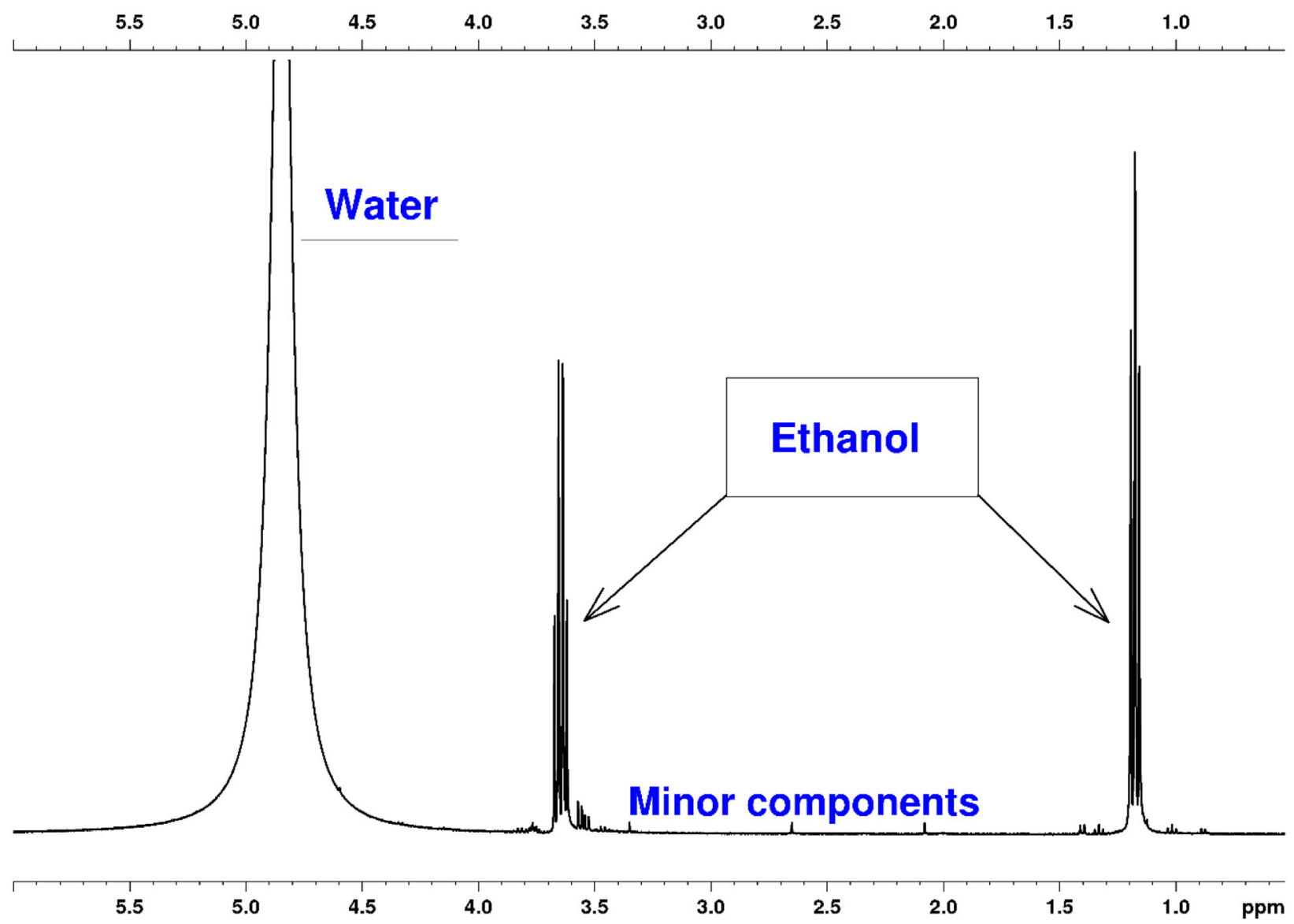

F I G U R E 2 Typical proton NMR spectrum of wine sample without water and ethanol suppression

wood of the oak barrels in which it is being aged. Other types of compounds may be extracted from cork; these are various derivatives of terpenes, polyphenols, and others. There were recent reports about the reactivity of such extracts with compounds in wine (Azevedo et al., 2017) and a more comprehensive study using a metabolomic approach (Pinto et al., 2019), including NMR spectroscopy, to study the impact of the corks on wine.

\subsection{1 | Quantitative analysis (targeted approach)}

NMR spectroscopy is often used for the quantitative analysis of individual substances in mixtures. Here, the intensity of a resonance signal, which corresponds to the area under the signal curve, is used: Under specific conditions, the number of protons contributing to the signal can be deduced from the integral. An internal standard can be used for quantification, if added to the sample in a specific quantity. The analyte signals resonance assignment and the standard must be known. The signals selected for quantification should be free from overlapping or suitable methods for integrating overlapping signals must be used (e.g., deconvolution).

The quantification of components can also be carried out without internal chemical standards for quantification, by applying the so-called PULCON method, which relies on the absolute intensities of two different spectra, of the sample to be quantified and of the standard sample used for response calculation (Dreier \& Wider, 2006). qNMR spectroscopy is a relative primary method (Pauli, Jaki, \& Lankin, 2005, 2012): the analyte can be correlated directly to the calibration standard, thus eliminating the need for external standards and calibration curves (Godelmann, Kost, Patz, Ristow, \& Wachter, 2016).

The quantitative determination of wine components (socalled wine metabolites) by ${ }^{1} \mathrm{H}$ NMR spectroscopy makes it possible to perform wine authentication and control by comparing the measured contents with the official regulatory limits (e.g., methanol) or with established indicator values (e.g., shikimic acid). Suitability of specific compounds for quantification is determined by such factors as signal multiplicity (singlets or simple multiplets are preferable to complex multiplets), possibility of signal integration (i.e., the signal to be integrated should 


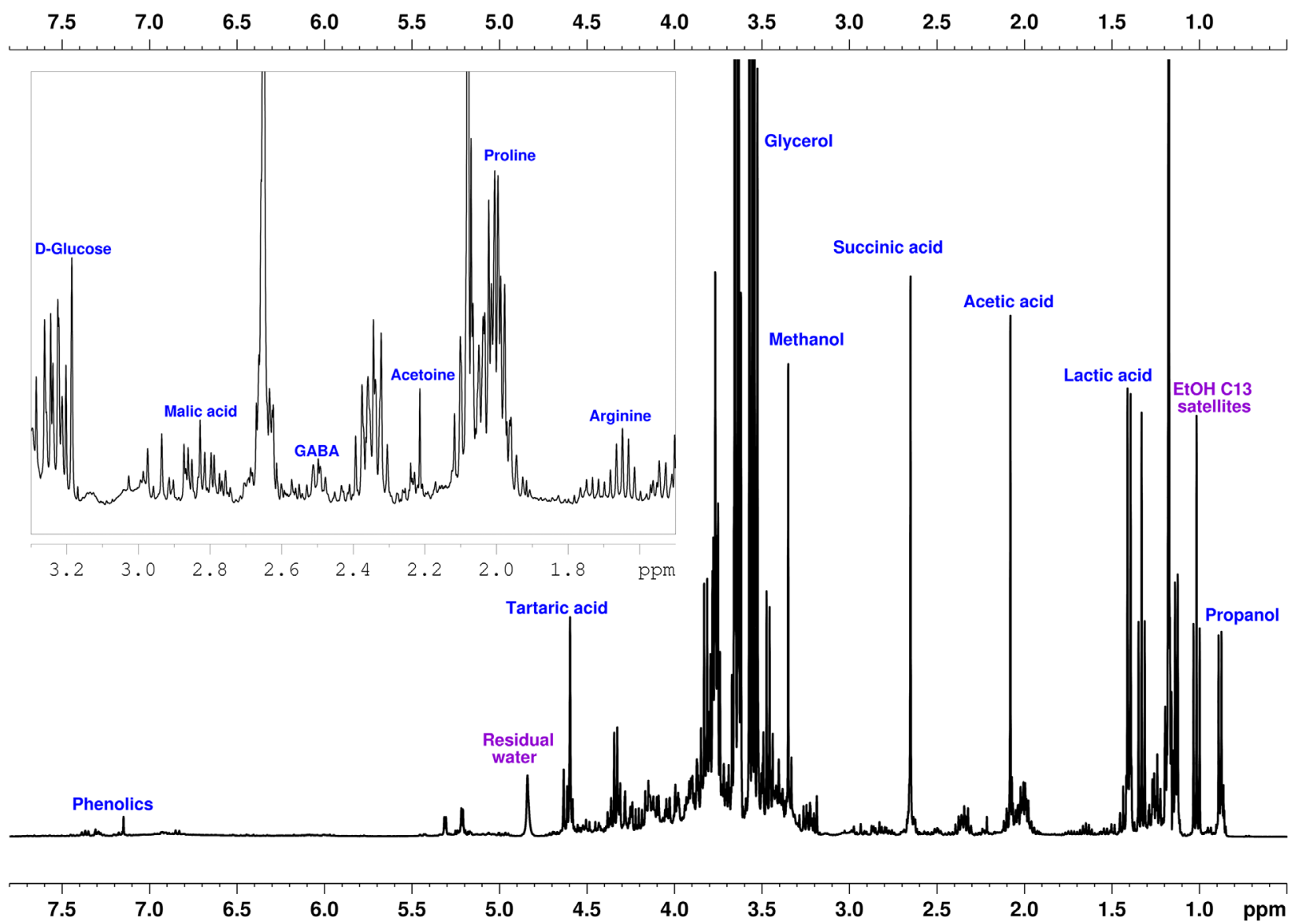

F I G U R E 3 Typical proton NMR spectrum of wine sample with water and ethanol suppression

not overlap with adjacent one) and signal location (i.e., it should not be situated near the suppressed water or ethanol signals, as it distorts the integral value). Examples of compound classes are acids (acetic, lactic, malic, and fumaric), carbohydrates (glucose, fructose, sucrose), alcohols (2,3-butanediol, methanol, ethanol) (Godelmann et al., 2013; 2016). In addition, combining the quantitative ${ }^{1} \mathrm{H}$ NMR spectroscopy approach with various chemometric methods (profiling), such as principal component analysis (PCA) and partial least squares (PLS), makes it possible to identify various wine products parameters, such as, for example, geographical origins (terroir in wines) (Fotakis et al., 2013; Gougeon et al., 2018; Gougeon, da Costa, Guyon, \& Richard, 2019a; Sobolev et al., 2019), and grape varieties (Amargianitaki \& Spyros, 2017; Aru, Sørensen, Khakimov, \& Toldam-Andersen, 2018; Magdas, Pirnau, Feher, Guyon, \& Cozar, 2019). Vintage identification by ${ }^{1} \mathrm{H}$ NMR is also possible: as the weather and soil conditions change from one harvest year to another, so do certain metabolites in the resulting wine. For example, concentrations of lactic acid, 2,3-butanediol, proline, and some other components for 2006 and 2007 vintages of Meoru Korean wines were quite different, thus allowing to separate one from the other (Lee, Hwang, van den Berg, Lee,
\& Hong, 2009); also, changes in polyphenol levels made it possible to separate 2005 and 2006 vintages of Agiorgitiko wines (Anastasiadi et al., 2009). Analogously, similar compound classes were found (with the aid of PCA) to change from one vintage year to another in Riesling and Müller-Thurgau German wines (Godelmann et al., 2013).Wine aging is a much less studied field; nevertheless, it was possible to identify several compounds that undergo changes in concentration during short-term aging such as 5-hydroxymethyl-2-furfural in Cava sparkling wines (Serra-Cayuela et al., 2013), acetaldehyde and formate in Rioja and Priorat red wines (Kioroglou, Mas, \& Portillo, 2020). An analogous targeted analysis of wine aging was also carried out with support of PCA (Cassino, Tsolakis, Bonello, \& Gianotti, 2019; Godelmann et al., 2013). The case of aged wines from wine rarity collections appeared to be much more challenging (though still possible) due to variability in aging even within one batch as it was demonstrated on the case of several Château Mouton Rothschild wines (Gougeon, da Costa, Richard, \& Guyon, 2019b). An interesting proposal of a specific NMR magnet design to measure the contents of acetic acid, ethanol, and other constituents in wine without opening the bottles should also be noted (Sobieski, Mulvihill, Broz, \& Augustine, 
2006; Weekley, Bruins, \& Augustine, 2002; Weekley, Bruins, Sisto, \& Augustine, 2003).

The effects of various grape growing techniques on the metabolites in berries were also investigated using ${ }^{1} \mathrm{H}$ NMR spectroscopy. The examples are metabolic changes that occur in grapes due to genetic engineering (Picone et al., 2016), the differences in organic and biodynamic approaches to the cultivation of grape berries (Picone et al., 2016), the effect of fertilization on berry characteristics (Ciampa et al., 2019), and the metabolomic changes due to terroir and years of harvest (Mazzei et al., 2019).

There is also one example of using NMR spectroscopy for investigating ancient oenological practices (Jeandet et al., 2015). One hundred sixty-eight bottles of champagne were found in a shipwreck discovered in the Baltic Sea. The contents of three bottles were thoroughly analyzed using an array of analytical methods including, among others, NMR spectroscopy, both 1-dimensional proton and 2-dimensional correlations. The NMR studies provide information about concentration of ethanol, sugars, and 5-hydroxymethylfurfural in the samples (if present). Together with the information from other analytical methods, it became possible to decipher some of the steps of the winemaking processes used by that particular producer in the early 19 th century.

\subsection{2 | Metabolic fingerprinting (nontargeted approach)}

The typical profiling approach uses quantitative information on identified metabolites for the subsequent multivariate statistical evaluations (discrete analytical input parameters), whereas nontargeted approaches are based on the broad and unassigned input of spectral data in the form of features (Esslinger et al., 2014; Riedl et al., 2015). However, the evaluation of the acquired spectral NMR data, the fingerprints, also needs a dedicated statistical data preprocessing to reduce the data size and compensate for differences, e.g., slight signal shifts, unequal baselines, and noise. The most widely used mathematical approach to reduce the acquired data size and to minimize peak shift effects in NMR spectroscopy is the so-called bucketing (or binning) method. Bucketing is based on dividing a spectrum into segments (so-called bins or buckets) and taking the sum, mean, or integral area of the spectrum for each segment for further evaluation. This procedure results in a significantly reduced number of data points (the typically used bucket size is $0.04 \mathrm{ppm}$ ). A major drawback of bucketing might be the loss of a considerable amount of information compared with the original spectra. Some minor peaks shifts can be beneficially removed by bucketing. However, in some cases, the borders of the buckets are fixed and applied rigorously and automatically, irrespective of potential $\mathrm{pH}$-related deviations. This means that an incorrect alignment can lead to erroneous bucket loads (Esslinger et al., 2014; Smolinska, Blanchet, Buydens, \& Wijmenga, 2012). Advanced bucketing approaches consider peak shapes for segment definition and thereby the bucket borders are typically set in baseline regions (Davis et al., 2007; De Meyer et al., 2008).

Nevertheless, advance bucketing works only with a defined set of spectra for which the bucketing is optimized. When a new spectrum (from a different sample), with an extra signal due to adulteration, is to be analyzed, advanced bucketing may not fit well or, even worse, the chemical shift region in question (with the extra signal) could have been eliminated completely by the advanced bucketing and not be considered at all. In the latter case, an extra signal will not be detected. This disadvantage leads to a limited use of this approach in authentication strategies (Davis et al., 2007; De Meyer et al., 2008).

After NMR spectroscopic measurement, even with data preprocessing, the resulting data matrices still comprise numerous variables (depending on the bucket width), possibly including analytical results as well as, in some cases, metadata (e.g., variety, geographical origin, vintage).

Multivariate statistics is usually performed after data preprocessing. Because these approaches are based on the variance in the data space, a check with respect to the identification of outliers is to be carried out as a first step. Reasons for outliers can be: unperformed water and ethanol suppression during acquisition, erroneous $\mathrm{pH}$ adjustment or sample spoilage. These types of outliers are also detectable by applying PCA, which is typically performed as a first step to obtain an overview on the acquired data as exploratory analysis.

Multivariate statistics can generally be divided into unsupervised and supervised methods. Unsupervised methods aim at identifying patterns in the data that do not assume any a priori knowledge of the data. There are several tools useful for exploring the data such as PCA, factor analysis (FA) and hierarchical cluster analysis (HCA). They are variable reduction techniques defining a number of latent variables by making linear combinations of the original variables.

In contrast, supervised methods use calibration or training sets with known information (e.g., about variety or vintage) to build a classification model. Then, the model is tested and validated using an independent sample set, also with known information. The most popular supervised classification techniques include linear discriminant analysis (LDA), partial least squares-discriminant analysis (PLS-DA), and soft independent modeling of class analogy (SIMCA). An appropriate validation of the mathematical models is essential in the application of multivariate 
statistics. Only the validation process makes it possible to obtain a reliable and sustainable development of predictive models for future samples required for official control. One fair option for doing so is the creation of two data sets, one training set, consisting of $2 / 3$ of the analyzed samples, which is used to generate the classification model, and one test set of $1 / 3$ of the data to prove the predictive ability of the model. This approach is called "external validation" (Esslinger et al., 2015). If repeatedly performed using resampling strategies, valuable uncertainty information for the predictions can be revealed (Harrington, 2018; Westad \& Marini, 2015).

When interpreting statistical data, it is important to be able to detect both known and unknown (unforeseen) adulterations using the respectively established mathematical model. Typical multivariate methods (e.g., DA, LDA, PLS-DA, SIMCA) perform better with a previous training (by internal or external validation) of the adulteration of interest. That implies that the relevant deviation from the product is already known. Using these trained models to detect unforeseen adulterations that have not been trained might lead to false-positive or false-negative results. Some approaches try to resolve this particular problem by univariate data evaluation, e.g., quantile plot, z-score, or by single parameters derived from the multivariate statistical process control, e.g., Mahalanobis distance (Dordevic, Wehrens, Postma, Buydens, \& Camin, 2012) and distance to the model of X-space (DModX). DModX describes the distance of the observation from the $\mathrm{X}$ model plane or hyperplane and is also known as the residual error or the residual standard deviation (Charlton, Robb, Donarski, \& Godward, 2008). The evaluation of the results is similar to that of the Mahalanobis distance approaches, in that evaluation criteria are to be defined, e.g., a maximum value of DModX for the unadulterated/authentic samples is to be considered as the critical limit above which a test sample could be considered as suspect.

Different questions of wine authentication have been addressed with nontargeted approaches, concerning, for example, the wine terroir, the grape variety, and other properties (Cagliani, Scano, \& Consonni, 2017; Fan et al., 2018; Ralli et al., 2018). To study the effects of soil on wine metabolome, Pereira and colleagues applied PCA and PLS to a selection of French wine varieties (Cabernet Sauvignon, Cabernet Franc, and Merlot), limiting the spectral window to organic acids and aromatic areas (Pereira et al., 2007), without taking into account minor volatile metabolites. Son and coauthors (Son et al., 2008) studied 28 red wines from different regions (California, Australia, France, and Korea) with ${ }^{1} \mathrm{H}$ NMR spectroscopy using PCA and PLS-DA analysis, and were able to clearly separate regions and grape varieties. Anastasiadi et al. investigated red and white wines such as Agiorgitiko, Mandilaria,
Moschofilero, and Asyrtiko from the Greek wine making regions of Nemea and Santorini, applying PCA and PLSDA (Anastasiadi et al., 2009). This made it possible to differentiate between wineries in a certain region, as well as between vintages within the same variety. Rochfort and colleagues (Rochfort, Ezernieks, Bastian, \& Downey, 2010) used $800 \mathrm{MHz}{ }^{1} \mathrm{H}$ NMR spectroscopy for the Cabernet Sauvignon and Shiraz varieties of the Sunraysia region of Australia to study the effect of grape variety on the sensory attributes of wines. The 0.5 to $5 \mathrm{ppm}$ spectral region was used to evaluate the relevant variables using PCA and PLS-DA. The classification results was in agreement with the ones obtained by sensory analysis. Ali et al. applied ${ }^{1} \mathrm{H}$ NMR spectroscopy to 59 white wine samples (Riesling and Müller-Thurgau) from the German Palatinate region using PCA with Pareto scaling, PLS, and Orthogonal projections to latent structures with Unit Variance (UV) scaling for statistical data analysis (Ali, Maltese, Toepfer, Choi, \& Verpoorte, 2011). It was possible to identify which specific components contributed most to the differences in quality, varieties, and vintage. Koda, Furihata, Wei, Miyakawa, and Tanokura (2012) applied NMR spectroscopy-based profiling $\left({ }^{1} \mathrm{H}\right.$ NMR and $\mathrm{F}_{2}$-selective TOCSY) to rice wine samples, using bucketing and normalization to a constant sum as data preprocessing and then performed PCA, which provided information on which varieties of raw materials were used in the wine production. $\mathrm{Hu}$ and colleagues used ${ }^{1} \mathrm{H}$ NMR spectroscopy in combination with multivariate statistical analysis (PCA and PLS-DA) and HCA to study the genotype of various grape varieties, such as Merlot, Ruby Cabernet, Syrah, and Zinfandel and were able to separate the varieties that differ in components associated only with genetic differences (Hu et al., 2015). Geana et al. (2016) analyzed 56 samples of red wines using NMR spectroscopy coupled with LDA. This study has shown a differentiation between varieties, such as Cabernet Sauvignon, Merlot, Feteasca Neagra, Pinot Noir, Mamaia as well as different vintages. Wine evolution in amphorae was also studied by Baiano et al. (2015) using a combination of methods including NMR fingerprinting in order to determine the container effect. Fan et al. (2018) subjected 99 red and 71 Chinese white wine samples to NMR analysis with subsequent segment-wise peak alignment followed by PCA and LDA for separating red and white wine samples as well as different varieties. The average correct classification rates for red and white wines did not differ significantly using internal leave-one-out cross-validation (LOOCV, $82 \%$ and $94 \%$, respectively) as well as external repeated double random cross-validation (RDRCV, $83 \%$ and $90 \%$, respectively). In one of the latest studies by Hu et al., the effect of various yeasts in Chardonnay wines from China were investigated by nontargeted ${ }^{1} \mathrm{H}$ NMR spectroscopy and PCA/PLS-DA (Hu, Cao, Zhu, Xu, \& Wu, 2019). 


\section{$2.3 \quad{ }^{13} \mathrm{C}$ NMR spectroscopy and other approaches}

Quantitative ${ }^{13} \mathrm{C}$ NMR spectroscopy has some specialties. The ${ }^{13} \mathrm{C}$ atoms couple with the bound protons and complex splitting occurs. For recording of ${ }^{13} \mathrm{C}$ spectra, protons are therefore usually decoupled so that only one signal (singlet) is obtained per chemically different ${ }^{13} \mathrm{C}$ atom. For quantitative investigations complete relaxation is important, which is why for some carbons pulses should be followed by very long waiting times. Another effect that influences quantitative ${ }^{13} \mathrm{C}$ NMR spectroscopy is the nuclear overhauser effect (NOE effect, polarization transfer from protons to ${ }^{13} \mathrm{C}$ ), which is produced when the protons are decoupled and can be different for different $\mathrm{C}$ atoms. The amplification of individual signals can lead to overor under-indications of the relevant ingredients (Zerbe \& Jurt, 2013).

${ }^{13} \mathrm{C}$ NMR spectroscopic analysis of wines and musts has been used to analyze main constituents such as ethanol and glycerol, but also for the determination of substances present in lower concentrations such as amino acids or some other organic acids (Chon, Poulard, \& Rabiller, 1996). Despite the simple sample preparation and elegant measurement, without interference from the dominant water signal, the application of ${ }^{13} \mathrm{C}$ NMR spectroscopic analysis of alcoholic beverages for quantification of ingredients has not been intensively pursued since the late 1980s (Rapp et al., 1988).

Another special application of ${ }^{13} \mathrm{C}$ NMR spectroscopy is the determination of the site-specific ${ }^{13} \mathrm{C} /{ }^{12} \mathrm{C}$ ratios in the two positions of the ethanol molecule (Caer, Trierweiler, Martin, \& Martin, 1991; Jezequel, Joubert, Giraudeau, Remaud, \& Akoka, 2017). This technique corresponds, in principle, to ${ }^{2} \mathrm{H}$ SNIF NMR spectroscopy, although sitespecific determination of carbon requires an IRMS analysis of the absolute ${ }^{13} \mathrm{C} /{ }^{12} \mathrm{C}$ ratios of ethanol in addition to the sophisticated NMR measurement, as so far it has been impossible to use an internal NMR standard for the direct calculation of the ${ }^{13} \mathrm{C} /{ }^{12} \mathrm{C}$ ratios (Thomas et al., 2010; Zhang, Trierweiler, Jouitteau, \& Martin, 1999). Very recently a new approach was presented which includes the use of an internal standard and the combination of quantitative ${ }^{1} \mathrm{H}$ NMR and ${ }^{13} \mathrm{C}$ NMR (Jezequel et al., 2017) for internal calculation. However, to date, the site-specific ${ }^{13} \mathrm{C}$ ratio in ethanol only gives limited information for the appreciation of certain products deriving from Crassulacean acid metabolism plants, e.g., pineapple, in which the ${ }^{13} \mathrm{C} /{ }^{12} \mathrm{C}$ ratio of the two positions is different compared with cane sugar or maize alcohol (Thomas et al., 2010). It has been used only occasionally for wines so far (Gilbert et al., 2011), but it has not revealed more information compared with the global ${ }^{13} \mathrm{C} /{ }^{12} \mathrm{C}$ ratio of ethanol obtained by IRMS in terms of vine water status, for example (Guyon et al., 2015).

Additional developments were proposed, such as combinations of NMR spectroscopy with other well-established analytical methods. One example is the parallel application of stable isotope ratio analysis and ${ }^{1} \mathrm{H}$ NMR spectroscopy (Monakhova et al., 2014), where over 1,300 wine samples were analyzed by ${ }^{1} \mathrm{H}$ NMR spectroscopy, and over 700 of these were additionally investigated using SNIF NMR spectroscopy as well as IRMS $\left(\mathrm{D} / \mathrm{H},{ }^{13} \mathrm{C} /{ }^{12} \mathrm{C}\right.$, and ${ }^{18} \mathrm{O} /{ }^{16} \mathrm{O}$ ). Subsequently, the collected data were processed using the LDA, PLS-DA, FDA, and ICA statistical techniques. Here, the evaluation of fused analytical data resulted in a significant improvement of the ability to identify the geographical origin and vintage compared with the statistical analysis of distinct data sets.

Another development occurred in 2017, when liquid chromatography (LC)-solid-phase extraction (SPE)NMR spectroscopy was combined with mass spectrometry (specifically, time-of-flight mass spectrometry) (Kessler \& Godejohann, 2018). Here, ${ }^{1} \mathrm{H}$ NMR spectroscopy functioned in combination with the other techniques as part of the computer-assisted structure elucidation system. Apart from the usual 1D proton experiments, the authors employed 2D correlational experiments such as $\left[{ }^{1} \mathrm{H},{ }^{13} \mathrm{C}\right]$ heteronuclear single-quantum correlation (HMBC) and $\left[{ }^{1} \mathrm{H},{ }^{13} \mathrm{C}\right]$ heteronuclear multiple bond correlation (HMBC) to identify new markers in Corvina and Primitivo wine samples. Though the procedure is quite lengthy, the structure elucidation is automatic and user-friendly. Identification of new compounds in such complex organic mixtures as wines will aid in further honing the available detection arsenal.

Another recent study demonstrates the potential of ${ }^{1} \mathrm{H}$ NMR spectroscopy in combination with GC-MS for determining various metabolites and aroma components, in order to differentiate between several types of yeasts used for the production of sparkling wine samples (Schmitt et al., 2019). In addition, ${ }^{1} \mathrm{H}$ NMR spectroscopy was successfully used as a reference method for ${ }^{13} \mathrm{C}$ NMR spectroscopy, to determine the quantities of several fructose isomers and ethanol in wine (Colombo, Aupic, Lewis, \& Pinto, 2015).

\section{4 | Commercial application}

As mentioned in the introduction, around ten years ago, the Bruker Corporation developed a $400 \mathrm{MHz}$ NMR spectrometer-based automated quality control tool for fruit juices, initially called "SGF Profiling" (Humpfer et al., 2009; Spraul et al., 2009), which is now available on the 
market as "JuiceScreener" (Monakhova et al., 2014). It combined both quantitative (targeted) and nontargeted ${ }^{1} \mathrm{H}$ NMR analysis, and it turned out (Spraul et al., 2009) that the technique employed for juices could also be used for other food products, provided that they are soluble or at least semisoluble. Quite soon afterward, Bruker released the "WineScreener" or "Wine Profiling" system (Hofmann, 2015), which can quantify over 50 parameters with only one measurement; then, via subsequent statistical analysis it is possible to verify the geographical origin of wine products on a countrywide scale and, within a country (Link, Spraul, Schaefer, Fang, \& Schuetz, 2013), the grape variety and vintage of worldwide wine samples.

The "WineScreener" system follows a standardized and widely automated workflow. Sample preparation is rather simple. It consists of the addition of a buffer solution to the wine sample and a subsequent adjustment of the $\mathrm{pH}$ value to 3.1 by adding an acidic or alkaline solution. Afterward, an aliquot of the solution is transferred into a NMR tube and subjected to ${ }^{1} \mathrm{H}$ NMR data acquisition (400 MHz spectrometer). Four experiments with different pulse programs and acquisition and processing parameters are performed automatically. The statistically evaluated NOE spectrum is recorded with 32 scans and 8-fold signal suppression of water and ethanol methylene and methyl group signals. After recording the spectra file in the laboratory, in the routine workflow, all spectra files together with the respective wine properties are sent to a centralized data evaluation process. This fully automated process results in quantitative for certain ingredients and predicts wine properties in a report file to the customer. Besides this routine-friendly workflow, the "WineScreener" system relies on a reference database composed of wine spectra from various varieties, origin, and vintages. For example, as of 2015 it contained 13,000 spectra for five countries and regions (Germany, Austria, France, Italy, and Spain) (Minoja \& Napoli, 2014; Spraul, Link, Schaefer, Fang, \& Schuetz, 2015), and about 19,000 entries as of 2019. These reference data are used to plot a distribution of quantitative parameters for comparable wines as well as to create and validate statistical models for wine properties prediction.

The "WineScreener" system relies on standardized and automated chemical and data analysis routines in conjunction with a reference database. This commercial, ready-touse system has the advantage that only a ${ }^{1} \mathrm{H}$ NMR measurement of the wine sample is needed to assess multiple aspects of wine composition, quality, and adulteration. The system was created to be "lab-, user- and instrumentindependent" within one vendor of course (Spraul et al., 2015), but a strict protocol must be followed, and in addition certain specified equipment (e.g., suited type of spectrometer) of one vendor is a prerequisite. It can analyze many samples within a short time (about half an hour per sample measurement). The data analysis, combined with the cost of the samples, is licensed and performed without user interaction in a closed workflow that also includes the use of a comparison database owned and maintained by the provider. Thus, the "WineScreener" system offers a user-friendly solution for routine applications, even though, on the one hand, it lacks full transparency within the data evaluation process and, on the other hand, the evaluation is based on a proprietary database operated by a private company. These two factors are currently limiting its use in official wine controls.

\section{3 | CHALLENGES AND FUTURE PERSPECTIVES}

\section{1 | Validation concepts, quality assurance, and harmonization}

A prerequisite for the application of an analytical method in official wine control is its recognition as a validated method by the standardization body, which, for wine, is the International Organization for Wine and Vine (OIV). Currently, the only NMR spectroscopy-based approach that is recognized as an official method to verify the authenticity of wine is the SNIF NMR spectroscopic method. It was adopted in the 1990s by the European Commission (1990, 2009), and also by the International Organization of Vine and Wine (OIV, 2019c). ${ }^{1} \mathrm{H}$ NMR spectroscopybased methods for wine authentication have not been recognized as official standards, yet. However, several steps have already been taken. A ${ }^{1} \mathrm{H}$ NMR method comparable to the operating principle of the "WineScreener" system, comprising both quantitative and fingerprinting analysis, has been successfully applied in scientific wine authentication studies. Bruker laboratories received its "WineProfiling" accreditation according to ISO/IEC 17025 in 2016 (Deutsche Akkreditierungsstelle $\mathrm{GmbH}, 2019$ ) and the technology is now offered by various companies, in the form of contract analysis. A first step for the validation of the targeted approach was taken in a collaborative wine compound quantification study published in 2016 (Godelmann et al., 2016). In this ring trial, 15 laboratories from various countries quantified six parameters (glucose, malic, acetic, fumaric, shikimic, and sorbic acids) in 10 wine samples. Quantification of the six target analytes was done by manual integration of selected signals independent from the automated data evaluations of service providers. The obtained precision parameters were acceptable according to established criteria. The authors claim that the method is suitable for white, red, and rosé wine types alike. Currently, this "Quantitation of glucose, malic acid, acetic acid, fumaric acid, shikimic acid and 
sorbic acid in wine using proton nuclear magnetic resonance spectroscopy" targeted method is in the final discussion phase within the OIV, pending its approval as the official method (Herbert-Pucheta, Mejía-Fonseca, ZepedaVallejo, Milmo-Brittingham, \& Maya, 2019). Generally, adoption of proprietary methods by standard-setting organizations such as Codex Alimentarius or the OIV requires compliance with special provisions (Food and Agriculture Organization of the United Nations \& World Health Organization, 2018), whereas here the discussion concerns only the targeted application for the six analytes, independent of one NMR vendor. Although the validation of the targeted approach is (more or less) straightforward, as it relies on traditional validation parameters such as limit of detection, limit of quantification, measurement uncertainty, accuracy with precision and trueness, the validation of the nontargeted approach is still challenging (Esslinger et al., 2014, 2015; Fauhl-Hassek, 2019; Riedl et al., 2015), as it lacks a commonly accepted, standardized procedure. In particular, there is a need for transparent model validation approaches, including algorithm independent performance parameters, and a need for robustness verification including long-term stability. Moreover, the databases which the predictions rely on need to be clearly characterized. There are few examples that present validation strategies for authentication methods based on nontargeted approaches (Alewijn, van der Voet, \& van Ruth, 2016; United States Pharmacopeia, 2019). Their generalization still needs to be demonstrated. The recognition of wine authentication methods based on nontargeted approaches might therefore have still a long way to go.

In addition to the validation of the analytical methods, quality assurance measures need to be established in routine analysis and official control laboratories. Here, in particular, maintenance strategies for the nontargeted approaches are needed to follow the long-term performance of multivariate models and update the models, if required. A possible solution to achieve quality assurance for nontargeted approaches is the inclusion of quality control samples. Their composition should be similar to that of the authentic samples being investigated, so that they can serve as performance control for the whole approach (including sample preparation and NMR measurement) with regard to repeatability and variance, as well as to timedependent drifts. Generally, the QC sample should have a certain shelf life and the stability of the matrix itself must be established. This is difficult because most foods are subject to alteration and spoilage over a certain period of time (Esslinger et al., 2014). Due to the fact that, especially in case of nontargeted analysis, the whole metabolome of the QC sample is used for evaluation, the aspect of spoilage and alteration, and its connected changes in the composition of the QC sample, have to be considered carefully.
There are only a few studies dealing with the implementation of quality assurance measures or the analyses and assessment of a QC sample in nontargeted analysis. Sangster and colleagues described a possible method to verify the readiness of the system for measurement, with a QC sample and subsequent exploratory data analysis (PCA). Unfortunately, this evaluation of measurement results is not based on fixed limit values (transferable to other areas or laboratories), but on the professional assessment of the analyst, so it is both uncertain and subjective. Here, the basic prerequisite for a reliable mathematical model is that the variance of the QC sample replicates (sample preparation and measurement) must be smaller than the natural variance of the "authentic" samples (Sangster, Major, Plumb, Wilson, \& Wilson, 2006).

\section{2 | Accessibility and applicability of data processing tools and workflows}

To profit from the advantages of ${ }^{1} \mathrm{H}$ NMR spectroscopy in routine applications and official controls, technical progress is needed in the joint processing of spectra data. Although wine sample preparation is quite simple and ${ }^{1} \mathrm{H}$ NMR spectroscopic measurement is fast and robust, data evaluation is complex and in most cases not yet routinefriendly. As previously discussed, so far, one proprietary solution is known that demonstrates the proof-of-principle for a routine-friendly wine authentication workflow. It relies on a solid standardized protocol from sample preparation to NMR measurement performed by the spectroscopist, followed by an automated spectra evaluation on a central proprietary platform. In this case, the user-friendly data evaluation process has strong limitations with regard to transparency. Meanwhile, many data evaluation tools have been developed that are often based on open-source scripts and that can be run in pipelined workflows, with various levels of user-friendliness.

The data evaluation process, from NMR spectra acquisition to prediction of wine properties, comprises several steps of spectra processing, data processing and statistical modeling for which a wide range of software tools are available. Recent reviews critically discuss these workflow steps and suitable bioinformatics tools for complex biological mixtures (Emwas et al., 2018; Mendez, Pritchard, Reinke, \& Broadhurst, 2019; PuchadesCarrasco, Palomino-Schätzlein, Pérez-Rambla, \& PinedaLucena, 2016; Ulaszewska et al., 2019). In research studies, it is currently common practice to combine several vendor and vendor-independent software solutions to perform processing and statistical analysis. Commercial GUI-based software such as AMIX and Assure (Biospin Corporation, Billerica, MA, USA), MNOVA (Mestrelab Research, 


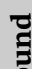
ํํㄹ

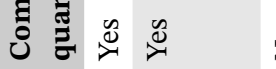
之

$\underbrace{\circ}$

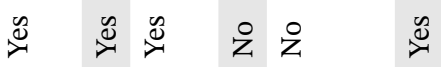

$\stackrel{0}{2}$

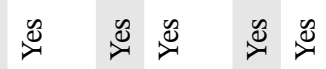

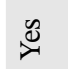

$\stackrel{2}{z}$

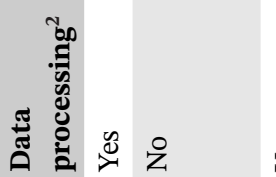

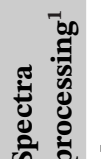

.

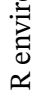

营

造

$\mathscr{n}$

¿

दे ₹

氝 
Santiago de Compostela, Spain), SIMCA (SartoriusUmetrics, Umeå, Sweden), Unscrambler (Camo Analytics, Oslo, Norway) as well as commercial command-line software such as MATLAB (MathWorks, Natick, MA, USA) are used. Moreover, a number of open-source packages have been developed based on the $\mathrm{R}$ programming language, distributed under the GNU General Public License (R Core Team, 2020), that are capable of spectra and data processing and/or statistical analysis of ${ }^{1} \mathrm{H}$ NMR spectra. For an overview of selected $\mathrm{R}$ packages see Table 1; for a more comprehensive collection, please refer to Hanson (2020). The available command-line tools span a wide range of functions and algorithms that can be combined to create flexible data evaluation processes. However, this requires thorough knowledge of the programming languages, which often prevents practitioners from using such tools.

To improve usability, web-based open-source tools such as MVAPACK (Worley \& Powers, 2014), Workflow4Metabolomics (Giacomoni et al., 2015), or NMRprocflow (Jacob, Deborde, Lefebvre, Maucourt, \& Moing, 2017), were developed, to, among other things, process and statistically analyze NMR spectroscopy-based metabolomics data in user-friendly workflows. Hereby, NMRprocflow overcomes some of the limitations of the steady web-based workflow tools. For instance, it allows a flexible combination of spectra and data processing steps for distinct chemical shift ranges and provides, in addition to the web-based access, processing capacity on a virtual machine and an $\mathrm{R}$ package for individual processing scripts.

With regard to these current developments, a combination of a web-based evaluation portal with underlying open-source scripts seems promising in order to create a transparent, flexible, and user-friendly data evaluation process for the specific application of wine authentication.

\section{3 | Data repositories}

Regardless of whether the analysis is performed in a targeted or nontargeted way, a building block of wine authentication using NMR spectroscopy is in most cases (except the verification of regulated maximum values) the comparison of the analytical results/measured data with a database (i.e. empirical values resulting from the analysis of a large number of other comparable and authentic samples). The "empirical" values are usually based on data/databases that are as representative as possible (Donarski, Camin, Fauhl-Hassek, Posey, \& Sudnik, 2019). These databases are indispensable, especially for nontargeted analysis and stable isotope analysis by NMR spectroscopy. The reason for this is that, among other things, the large variation of the samples (due to storage, vintage, oenological procedures, etc.) directly influences the measurement results/spectral information and thus the quality of mathematical models (increasing uncertainty of prediction ability).

However, the development of food authenticity databases is usually associated with certain requirements and hurdles (Donarski et al., 2019), especially considering the increasing need not only to manage and use data as an individual solution in one's own laboratory, but also to share them with other parties or actors in the food chain. Issues such as the definition of uniform data exchange formats and infrastructures, the choice of suitable standards and software to operate these databases, rights of use and licenses, determination of the institution responsible for maintenance, compliance with data protection regulations, and much more need to be resolved.

Basically, there are two approaches to database systems: (a) central database and (b) distributed/decentralized data storage. It is becoming increasingly apparent that central databases are no longer able to meet current and future requirements (i.e., due to limited scalability and the lack of data sovereignty of data owners).

Based on this, there are various studies and projects investigating the development of relevant structures and systems, i.e., EU projects Oleum (https://www. oleumproject.eu/), Food Integrity (https://secure.fera. defra.gov.uk/foodintegrity/index.cfm), COSMOS (https: //cosmos-fp7.eu/index.html), MEDIFIT (https://primamed.org/results-of-the-call-prima-section-1-2019/), as well as national projects such as the FoodAuthent project (https://www.foodauthent.de/web/guest/home).

\section{4 | CONCLUSION}

${ }^{1} \mathrm{H}$ NMR spectroscopy is a powerful tool for the analysis of food products, and of wine in particular, as demonstrated by multiple studies. This technology makes the analysis fast, in principle nondestructive and requires less sample treatment before measurement compared with classical chromatographic and mass spectrometric methods. It even has certain advantages over the classic ${ }^{2} \mathrm{H}$ SNIF NMR spectroscopy. The ${ }^{2} \mathrm{H}$ SNIF NMR spectroscopy approach is well established in official wine control and the isotopic information offers unique authentication of key features particularly in terms of the detection of nonauthorized chaptalization.

Wine authentication examples based on targeted as well as nontargeted ${ }^{1} \mathrm{H}$ NMR spectroscopic approaches show great potential for the fast identification of suspicious samples in official wine control, although up to now no methods have been adopted by standardization bodies. 
Currently, these techniques are not used on their own by control authorities to reject wines but they play a growing role as screening tools, indicating those samples that need to be investigated further with other official methods of analysis or traceability approaches. From an official control perspective, the current wine authentication process offered by the WineProfiling has its weaknesses with regard to the reliability and transparency of the entire data evaluation process and the reference databases. To promote the harmonization of this valuable approach there is a need for:

- accepted validation concepts for the targeted and nontargeted approach (includes quality parameters for analysis, spectra, etc.)

- standardized data evaluation processes integrated in transparent and user-friendly data processing workflows, and

- solutions for the joint usage and management of spectra collections.

Therefore, further efforts and the collaboration of multiple accredited international laboratories are necessary for official recognition and for the testing of the trustworthiness of this method.

\section{F U N D I N G}

The research was funded by the FESR 2014-2020 Program of the Autonomous Province of Trento (Italy) with EU cofinancing (Fruitomics).

\section{AUTHOR CONTRIBUTIONS}

Federica Camin conceived and designed the review, drafted the outline, and revised the article. Pavel Solovyev collected the literature and drafted the article. Carsten Fauhl-Hassek, Janet Riedl, and Susanne Esslinger revised significantly the drafted article, contributed in redesigning the review, and in providing literature and experience. Luana Bontempo reviewed the final article.

\section{CONFLICTS OF INTEREST}

The authors declare no conflicts of interest.

\section{ORCID}

Pavel A. Solovyev (10 https://orcid.org/0000-0001-7152-3157 Luana Bontempo (1) https://orcid.org/0000-0001-7583-1501 Federica Camin (1) https://orcid.org/0000-0003-0509-6745

\section{RE F E RE N C ES}

Alewijn, M., van der Voet, H., \& van Ruth, S. (2016). Validation of multivariate classification methods using analytical fingerprints Concept and case study on organic feed for laying hens. Journal of
Food Composition and Analysis, 51, 15-23. https://doi.org/10.1016/ j.jfca.2016.06.003

Ali, K., Maltese, F., Toepfer, R., Choi, Y. H., \& Verpoorte, R. (2011). Metabolic characterization of Palatinate German white wines according to sensory attributes, varieties, and vintages using NMR spectroscopy and multivariate data analyses. Journal of Biomolecular NMR, 49(3), 255-266. https://doi.org/10.1007/s10858-011-9487-

Amargianitaki, M., \& Spyros, A. (2017). NMR-based metabolomics in wine quality control and authentication. Chemical and Biological Technologies in Agriculture, 4(1), 9. https://doi.org/10.1186/s40538017-0092-x

Anastasiadi, M., Zira, A., Magiatis, P., Haroutounian, S., Skaltsounis, A., \& Mikros, E. (2009). ${ }^{1}$ H NMR-based metabonomics for the classification of Greek wines according to variety, region, and vintage. Comparison with HPLC data. Journal of Agricultural and Food Chemistry, 57(23), 11067-11074. https://doi.org/10.1021/jf902137e

Anders, U., Tittgemeier, F., \& Hailer, G. (1976). 1H-NMR Bestimmung von Äthanol in Wein, weinähnlichen Getränken und Spirituosen. Zeitschrift Für Lebensmittel-Untersuchung Und Forschung, 162(1), 21-24. https://doi.org/10.1007/BF01104356

Arapitsas, P., \& Mattivi, F. (2018). LC-MS Untargeted protocol for the analysis of wine. In Georgios A. Theodoridis, Helen G. Gika, \& Ian D. Wilson. (Eds.) Metabolic profiling (pp. 225-235). Springer.

Aru, V., Sørensen, K., Khakimov, B., \& Toldam-Andersen, T. (2018). Cool-climate red wines-Chemical composition and comparison of two protocols for 1H-NMR analysis. Molecules, 23(1), E160. https://doi.org/10.3390/molecules23010160

Arvanitoyannis, I. S. (2010). Wine authenticity, traceability and safety monitoring. In Andrew G. Reynolds (Ed.), Managing wine quality (pp. 218-270). Cambridge, United Kingdom: Woodhead Publishing Limited. https://doi.org/10.1533/9781845699284.2.218

Azevedo, J., Fernandes, A., Oliveira, J., Brás, N. F., Reis, S., Lopes, P., ... de Freitas, V. (2017). Reactivity of cork extracts with (+)-catechin and malvidin-3-O-glucoside in wine model solutions: Identification of a new family of ellagitannin-derived compounds (corklins). Journal of Agricultural and Food Chemistry, 65(39), 8714-8726.Retrieved from https://pubs.acs.org/doi/abs/10. 1021/acs.jafc.7b02845

Baderschneider, B., \& Winterhalter, P. (2001). Isolation and characterization of novel benzoates, cinnamates, flavonoids, and lignans from Riesling wine and screening for antioxidant activity. Journal of Agricultural and Food Chemistry, 49(6), 2788-2798. https://doi.org/10.1021/jf010396d

Baiano, A., Mentana, A., Quinto, M., Centonze, D., Longobardi, F., Ventrella, A., ... Del Nobile, M. A. (2015). The effect of in-amphorae aging on oenological parameters, phenolic profile and volatile composition of Minutolo white wine. Food Research International, 74, 294-305.Retrieved from https://doi.org/10.1016/ j.foodres.2015.04.036

Baker, R. H., Barkenbus, C., \& Roswell, C. A. (1940). A large spinningband fractionating column. Industrial and Engineering Chemistry, Analytical Edition, 12(8), 468-471. https://doi.org/10.1021/ ac50148a014

Beirnaert, C., Meysman, P., Vu, T. N., Hermans, N., Apers, S., Pieters, L., ... Laukens, K. (2018). speaq 2.0: A complete workflow for high-throughput 1D NMR spectra processing and quantification. PLoS Computational Biology, 14(3), e1006018. https://doi.org/10. 1371/journal.pcbi.1006018 
Belton, P. S., Colquhoun, I. J., Katherine Kemsley, E., Delgadillo, I., Roma, P., John Dennis, M., ... Spraul, M. (1998). Application of chemometrics to the $1 \mathrm{H}$ NMR spectra of apple juices: Discrimination between apple varieties. Food Chemistry, 61(1-2), 207-213. https://doi.org/10.1016/s0308-8146(97)00103-9

Belton, P. S., Delgadillo, I., Gil, A. M., Roma, P., Casuscelli, F., Colquhoun, I. J., ... Spraul, M. (1997). High-field proton NMR studies of apple juices. Magnetic Resonance in Chemistry: MRC, 35(13), S52-S60. https://doi.org/10.1002/(SICI)1097-458X(199712) 35:13\%3CS52::AID-OMR212\%3E3.0.CO;2-D

Belton, P. S., Delgadillo, I., Holmes, E., Nicholls, A., Nicholson, J. K., \& Spraul, M. (1996). Use of high-field 1H NMR spectroscopy for the analysis of liquid foods. Journal of Agricultural and Food Chemistry, 44(6), 1483-1487. https://doi.org/10.1021/jf950640z

Brüders, W. (1999). Der Weinskandal: Das Ende einer unseligen Wirtschaftsentwicklung. Linz: Denkmayr.

Cadiot, D., Callede, D., Nadeau, J.-P., \& Sebastian, P. (2004). System for cooling a heated juice by partial low-pressure evaporation. European Patent No. 1409099:A2.

Caer, V., Trierweiler, M., Martin, G. J., \& Martin, M. L. (1991). Determination of site-specific carbon isotope ratios at natural abundance by carbon-13 nuclear magnetic resonance spectroscopy. Analytical Chemistry, 63(20), 2306-2313. https://doi.org/10.1021/ ac00020a021

Cagliani, L. R., Scano, P., \& Consonni, R. (2017). NMR-based metabolomics: Quality and authenticity of plant-based foods. In G. Webb (Ed.), Modern magnetic resonance (pp. 1-20). Springer, Cham. https://doi.org/10.1007/978-3-319-28275-6_1-1

Camin, F., Boner, M., Bontempo, L., Fauhl-Hassek, C., Kelly, S. D., Riedl, J., \& Rossmann, A. (2017). Stable isotope techniques for verifying the declared geographical origin of food in legal cases. Trends in Food Science \& Technology, 61, 176-187. https://doi.org/10.1016/ j.tifs.2016.12.007

Cañueto, D., Gómez, J., Salek, R. M., Correig, X., \& Cañellas, N. (2018). rDolphin: A GUI R package for proficient automatic profiling of 1D 1H-NMR spectra of study datasets. Metabolomics: Official Journal of the Metabolomic Society, 14(3), 24. https://doi.org/ 10.1007/s11306-018-1319-y

Cassino, C., Tsolakis, C., Bonello, F., \& Gianotti, V. (2019). Wine evolution during bottle aging, studied by $1 \mathrm{H}$ NMR spectroscopy and multivariate statistical analysis. Food Research International, 116, 566-577. https://doi.org/10.1016/j.foodres.2018.08.075

Castillo-Muñoz, N., Gómez-Alonso, S., García-Romero, E., Gómez, M. V., Velders, A. H., \& Hermosín-Gutiérrez, I. (2008). Flavonol 3-O-glycosides series of Vitis vinifera cv. Petit Verdot red wine grapes. Journal of Agricultural and Food Chemistry, 57(1), 209219.Retrieved from https://pubs.acs.org/doi/abs/10.1021/jf802863g

Cavicchi, A., \& Santini, C. (2011). Brunellopoli: A wine scandal under the Tuscan sun. Tourism Review International, 15(3), 253267. https://doi.org/10.3727/154427211/13216636845747

Charlton, A. J., Robb, P., Donarski, J. A., \& Godward, J. (2008). Nontargeted detection of chemical contamination in carbonated soft drinks using NMR spectroscopy, variable selection and chemometrics. Analytica Chimica Acta, 618(2), 196-203. https://doi.org/10. 1016/j.aca.2008.04.050

Chon, C., Poulard, A., \& Rabiller, C. (1996). Quantitative analysis of the main components of the wines by means of carbon-13 NMR: Optimisation of the method. OENO One, 30(2), 73-83. https://doi. org/10.20870/oeno-one.1996.30.2.1107
Christoph, N., Hermann, A., \& Wachter, H. (2015). 25 Years authentication of wine with stable isotope analysis in the European Union-Review and outlook. BIO Web of Conferences, 5, 02020. https://doi.org/10.1051/bioconf/20150502020

Ciampa, A., Dell'Abate, M. T., Florio, A., Tarricone, L., Di Gennaro, D., Picone, G., ... Benedetti, A. (2019). Combined magnetic resonance imaging and high resolution spectroscopy approaches to study the fertilization effects on metabolome, morphology and yeast community of wine grape berries, cultivar Nero di Troia. Food Chemistry, 274, 831-839. https://doi.org/10.1016/j.foodchem. 2018.09.056

Colombo, C., Aupic, C., Lewis, A. R., \& Mario Pinto, B. (2015). In situ determination of fructose isomer concentrations in wine using 13C Quantitative nuclear magnetic resonance spectroscopy. Journal of Agricultural and Food Chemistry, 63(38), 8551-8559. https://doi.org/10.1021/acs.jafc.5b03641

Cretin, B. N., Waffo-Teguo, P., Dubourdieu, D., \& Marchal, A. (2019). Taste-guided isolation of sweet-tasting compounds from grape seeds, structural elucidation and identification in wines. Food Chemistry, 272, 388-395. https://doi.org/10.1016/j.foodchem.2018. 08.070

Davis, R. A., Charlton, A. J., Godward, J., Jones, S. A., Harrison, M., \& Wilson, J. C. (2007). Adaptive binning: An improved binning method for metabolomics data using the undecimated wavelet transform. Chemometrics and Intelligent Laboratory Systems, 85(1), 144-154. https://doi.org/10.1016/j.chemolab.2006.08.014

De Meyer, T., Sinnaeve, D., Van Gasse, B., Tsiporkova, E., Rietzschel, E. R., De Buyzere, M. L., ... Van Criekinge, W. (2008). NMR-based characterization of metabolic alterations in hypertension using an adaptive, intelligent binning algorithm. Analytical Chemistry, 80(10), 3783-3790. https://doi.org/10.1021/ac7025964

Deutsche Akkreditierungsstelle GmbH. (2019). Annex to the accreditation certificate D-PL-19229-01-00 according to DIN EN ISO/IEC 17025:2018 (No. D-PL-19229-01-00).

Donarski, J., Camin, F., Fauhl-Hassek, C., Posey, R., \& Sudnik, M. (2019). Sampling guidelines for building and curating food authenticity databases. Trends in Food Science \& Technology, 90, 187-193. https://doi.org/10.1016/j.tifs.2019.02.019

Dordevic, N., Wehrens, R., Postma, G. J., Buydens, L. M. C., \& Camin, F. (2012). Statistical methods for improving verification of claims of origin for Italian wines based on stable isotope ratios. Analytica Chimica Acta, 757, 19-25. https://doi.org/10.1016/j.aca. 2012.10.046

Dreier, L., \& Wider, G. (2006). Concentration measurements by PULCON using X-filtered or 2D NMR spectra. Magnetic Resonance in Chemistry: MRC, 44(S1), S206-S212. https://doi.org/10.1002/mrc. 1838

Du, R., Qiao, X., Zhao, F., Song, Q., Zhou, Q., Wang, Y., ... Zhou, Z. (2018). Purification, characterization and antioxidant activity of dextran produced by Leuconostoc pseudomesenteroides from homemade wine. Carbohydrate Polymers, 198, 529-536. https:// doi.org/10.1016/j.carbpol.2018.06.116

Du, R., Qiao, X., Zhao, F., Song, Q., Zhou, Q., Wang, Y., ... Zhou, Z. (2019). Corrigendum to "Purification, characterization and antioxidant activity of dextran produced by Leuconostoc pseudomesenteroides from homemade wine”. Carbohydrate Polymers, 216, 331. https://doi.org/10.1016/j.carbpol.2019.04.006

Ebeler, S. E. (2015). Analysis of grapes and wines: An overview of new approaches and analytical tools. In Advances in wine research 
(Vol. 1203, pp. 3-12). American Chemical Society. https://doi.org/ 10.1021/bk-2015-1203.ch001

Jackson, R. (2014). Wine science. Principles and applications (4th ed). Academic Press.

Emwas, A. H. M. (2015). The strengths and weaknesses of NMR spectroscopy and mass spectrometry with particular focus on metabolomics research. Methods in Molecular Biology, 1277, 161193. https://doi.org/10.1007/978-1-4939-2377-9_13

Emwas, A. H., Roy, R., McKay, R. T., Tenori, L., Saccenti, E., Gowda, G. A. N., ... Wishart, D. S. (2019). NMR Spectroscopy for metabolomics research. Metabolites, 9(7), 123. https://doi.org/10. 3390/metabo9070123

Emwas, A. H., Saccenti, E., Gao, X., McKay, R. T., dos Santos, V. A. P. M., Roy, R., \& Wishart, D. S. (2018). Recommended strategies for spectral processing and post-processing of 1D 1H-NMR data of biofluids with a particular focus on urine. Metabolomics: Official Journal of the Metabolomic Society, 14(3), Article No. 31. https:// doi.org/10.1007/s11306-018-1321-4

Esslinger, S., Fauhl-Hassek, C., \& Wittkowski, R. (2015). Authentication of wine by $1 \mathrm{H}-\mathrm{NMR}$ spectroscopy: Opportunities and challenges. In S. B. Ebeler, G. Sacks, S. Vidal, \& P. Winterhalter (Eds.), Advances in wine research (Vol. 1203, pp. 85-108). Washington, DC: American Chemical Society. https://doi.org/10.1021/bk-20151203.ch006

Esslinger, S., Riedl, J., \& Fauhl-Hassek, C. (2014). Potential and limitations of non-targeted fingerprinting for authentication of food in official control. Food Research International, 60, 189-204. https: //doi.org/10.1016/j.foodres.2013.10.015

European Commission. (1990). Commission Regulation (EEC) No 2676/90 of 17 September 1990 determining Community methods for the analysis of wines. Official Journal of the European Union, 272, 1-192.Retrieved from https://publications.europa.eu/en/publication-detail//publication/6528497d-1ece-4355-ab08-c73b3242f7ee

European Commission. (1991a). Commission Regulation (EEC) No $2347 / 91$ of 29 July 1991 on the collection of samples of wine products for the purposes of cooperation between Member States and for analysis by nuclear magnetic resonance, including analysis for the purposes of the Community databank. Official Journal of the European Union, $L$ 214, 32-38.Retrieved from https://eur-lex.europa.eu/legalcontent/EN/TXT/HTML/?uri=CELEX:31991R2347\&from=IT

European Commission. (1991b). Commission Regulation (EEC) No $2348 / 91$ of 29 July 1991 establishing a databank for the results of analyses of wine products by nuclear magnetic resonance of deuterium. Official Journal of the European Union, $L$ 214, 39-43.Retrieved from https://eur-lex.europa.eu/legalcontent/EN/TXT/HTML/?uri=CELEX:31991R2348\&from=IT

European Commission. (2000). Commission Regulation (EC) No 2729/2000 of 14 December 2000 laying down detailed implementing rules on controls in the wine sector. (2000). Official Journal of the European Union, L 316, 16-29.Retrieved from https://eur-lex.europa.eu/legal-content/EN/TXT/HTML/?uri= CELEX:32000R2729\&qid $=1562058977970 \&$ from $=\mathrm{EN}$

European Commission. (2008). Commission Regulation (EC) No 555/2008 of 27 June 2008 laying down detailed rules for implementing Council Regulation (EC) No 479/2008 on the common organisation of the market in wine as regards support programmes, trade with third countries, production potential and on controls in the wine sector. Official Journal of the European Union, L 170, 1-80.Retrieved from https://eur-lex.europa. eu/legal-content/EN/TXT/HTML/?uri=CELEX:32008R0555\&

from $=$ en

European Commission. (2009). Commission Regulation (EC) No $606 / 2009$ of 10 July 2009 laying down certain detailed rules for implementing Council Regulation (EC) No 479/2008 as regards the categories of grapevine products, oenological practices and the applicable restrictions. Official Journal of the European Union, 193, 1-59.Retrieved from https://eur-lex.europa.eu/eli/reg/2009/ $606 /$ oj

European Commission. (2018). Commission Implementing Regulation (Eu) 2018/274 of 11 December 2017 laying down rules for the application of Regulation (EU) No 1308/2013 of the European Parliament and of the Council as regards the scheme of authorisations for vine plantings, certification, the inward and outward register, compulsory declarations and notifications, and of Regulation (EU) No 1306/2013 of the European Parliament and of the Council as regards the relevant checks, and repealing Commission Implementing Regulation (EU) 2015/561. Official Journal of the European Union, L 58, 60-95.Retrieved from https://eur-lex.europa.eu/ legal-content/EN/TXT/?uri=CELEX\%3A32018R0274

European Commission. (2019). 2019 Annual Report. The EU food fraud network and the system for administrative assistance - Food fraud. Retrieved from https://ec.europa.eu/food/sites/food/files/ safety/docs/ff_ffn_annual-report_2019.pdf

European Commission Directorate-General for Agriculture and Rural Development. (2019). November 2019 wine market update. Retrieved from https://ec.europa.eu/info/sites/info/files/foodfarming-fisheries/farming/documents/wine-dashboard_en.pdf

European Commission's science and knowledge service. (2018). Monthly summary of articles on food fraud and adulteration September 2019. Retrieved from https://ec.europa.eu/ knowledge4policy/publication/food-fraud-summary-september2019_en

European Commission's science and knowledge service. (2019a). Monthly summary of articles on food fraud and adulteration. Retrieved from https://ec.europa.eu/knowledge4policy/ publication/food-fraud-summary-january-2019_en

European Commission's science and knowledge service. (2019b). Monthly summary of articles on food fraud and adulteration. Retrieved from https://ec.europa.eu/knowledge4policy/ publication/food-fraud-summary-february-2019_en

European Commission's science and knowledge service. (2019c). Monthly Summary of articles on food fraud and adulteration March 2019. Retrieved from https://ec.europa.eu/ knowledge4policy/publication/food-fraud-summary-march2019_en

European Commission's science and knowledge service. (2019d). Monthly summary of articles on food fraud and adulteration May 2019. Retrieved from https://ec.europa.eu/knowledge4policy/ publication/food-fraud-summary-may-2019_en

European Commission's science and knowledge service. (2019e). Monthly summary of articles on food fraud and adulteration July-August 2019. Retrieved from https://ec.europa. eu/knowledge4policy/publication/food-fraud-summary-julyaugust-2019_en

European Commission's science and knowledge service. (2019f). Monthly summary of articles on food fraud and adulteration 
October 2019. Retrieved from https://ec.europa.eu/ knowledge4policy/publication/food-fraud-summary-october2019_en

European Commission's science and knowledge service. (2019g). Monthly summary of articles on food fraud and adulteration November-December 2019. Retrieved from https://ec.europa.eu/knowledge4policy/publication/food-fraudsummary-november-december-2019_en

European Commission's science and knowledge service. (2020a). Monthly summary of articles on food fraud and adulteration February 2020. Retrieved from https: //ec.europa.eu/knowledge4policy/food-fraud-quality/food-

fraud-summary-february-2020_en

European Commission's science and knowledge service. (2020b). Monthly summary of articles on food fraud and adulteration July-August 2020. Retrieved from https://ec.europa.eu/knowledge4policy/food-fraud-quality/foodfraud-summary-july-august-2020_en

European Commission's science and knowledge service. (2020c). Monthly summary of articles on food fraud and adulteration September 2020. Retrieved from https: //ec.europa.eu/knowledge4policy/food-fraud-quality/foodfraud-summary-september-2020_en

European Commission's science and knowledge service. (2020d). Monthly summary of articles on food fraud and adulteration October 2020. Retrieved from https://ec.europa.eu/knowledge4policy/ food-fraud-quality/food-fraud-summary-october-2020_en

European Union Intellectual Property Office. (2020). 2020 Status report on IPR infringement. Publications Office of the European Union. Retrieved from https://euipo.europa.eu/tunnelweb/secure/webdav/guest/document_library/observatory/ documents/reports/2020_Status_Report_on_IPR_infringement/ 2020_Status_Report_on_IPR_infringement_en.pdf

Everstine, K., Spink, J., \& Kennedy, S. (2013). Economically motivated adulteration (EMA) of food: Common characteristics of EMA incidents. Journal of Food Protection, 76(4), 723-735. https: //doi.org/10.4315/0362-028X.JFP-12-399

Fabre, S., Absalon, C., Pinaud, N., Venencie, C., Teissedre, P.-L., Fouquet, E., \& Pianet, I. (2014). Isolation, characterization, and determination of a new compound in red wine. Analytical and Bioanalytical Chemistry, 406(4), 1201-1208. https://doi.org/10.1007/ s00216-013-7244-Z

Fan, S., Zhong, Q., Fauhl-Hassek, C., Pfister, M. K. H., Horn, B., \& Huang, Z. (2018). Classification of Chinese wine varieties using $1 \mathrm{H}$ NMR spectroscopy combined with multivariate statistical analysis. Food Control, 88, 113-122. https://doi.org/10.1016/j.foodcont. 2017.11.002

Fauhl-Hassek, C. (2019). Quo vadis non-targeted wine analysis? BIO Web of Conferences, 12, 02030. https://doi.org/10.1051/bioconf/ 20191202030

Flamini, R. (2008). Hyphenated techniques in grape and wine chemistry. John Wiley \& Sons.

Food and Agriculture Organization of the United Nations, \& World Health Organization. (2018). Procedural manual of the codex alimentarius commission (26th ed.). Food \& Agriculture Org.

Forino, M., Gambuti, A., \& Moio, L. (2019). NMR-based systematic analysis of bioactive phytochemicals in red wine. First determination of xanthurenic and oleanic acids. Food Chemistry, 278, 497501. https://doi.org/10.1016/j.foodchem.2018.11.103
Fotakis, C., Kokkotou, K., Zoumpoulakis, P., \& Zervou, M. (2013). NMR metabolite fingerprinting in grape derived products: An overview. Food Research International, 54(1), 1184-1194. https:// doi.org/10.1016/j.foodres.2013.03.032

Fougere, E., Kaplan, E. K., \& Collins, C. A. (2020). Pricing uncertainty in wine markets following the Rudy Kurniawan scandal. Journal of Wine Research, 31(1), 1-5. https://doi.org/10.1080/09571264.2019. 1684249

Gammacurta, M., Waffo-Teguo, P., Winstel, D., Cretin, B. N., Sindt, L., Dubourdieu, D., \& Marchal, A. (2019). Triterpenoids from Quercus petraea: Identification in wines and spirits and sensory assessment. Journal of Natural Products, 82(2), 265-275. https://doi.org/ 10.1021/acs.jnatprod.8b00682

Geana, E. I., Popescu, R., Costinel, D., Dinca, O. R., Ionete, R. E., Stefanescu, I., ... Bala, C. (2016). Classification of red wines using suitable markers coupled with multivariate statistic analysis. Food Chemistry, 192, 1015-1024. https://doi.org/10.1016/j. foodchem.2015.07.112

Giacomoni, F., Le Corguillé, G., Monsoor, M., Landi, M., Pericard, P., Pétéra, M., ... Caron, C. (2015). Workflow4Metabolomics: A collaborative research infrastructure for computational metabolomics. Bioinformatics, 31(9), 1493-1495. https://doi.org/10.1093/bioinformatics/btu813

Gil, A. M., Duarte, I., Cabrita, E., Goodfellow, B. J., Spraul, M., \& Kerssebaum, R. (2004). Exploratory applications of diffusion ordered spectroscopy to liquid foods: An aid towards spectral assignment. Analytica Chimica Acta, 506(2), 215-223. https://doi. org/10.1016/j.aca.2003.11.006

Gilbert, A., Silvestre, V., Segebarth, N., Tcherkez, G., Guillou, C., Robins, R. J., ... Remaud, G. S. (2011). The intramolecular 13C-distribution in ethanol reveals the influence of the $\mathrm{CO}_{2}$-fixation pathway and environmental conditions on the site-specific $13 \mathrm{C}$ variation in glucose. In Plant, Cell \& Environment, 34(7), 1104-1112. https://doi.org/10.1111/j.1365-3040.2011. 02308.x

Glenn, N. A. (1963). Fractionator with plastic spinning band. US Patent No. 3080303.

Godelmann, R., Fang, F., Humpfer, E., Schütz, B., Bansbach, M., Schäfer, H., \& Spraul, M. (2013). Targeted and Nontargeted Wine Analysis by $1 \mathrm{H}$ NMR Spectroscopy combined with multivariate statistical analysis. differentiation of important parameters: Grape variety, geographical origin, year of vintage. Journal of Agricultural and Food Chemistry, 61, (23), 5610-5619. https://doi.org/10.1021/ jf400800d

Godelmann, R., Kost, C., Patz, C.-D., Ristow, R., \& Wachter, H. (2016). Quantitation of compounds in wine using (1)H NMR spectroscopy: Description of the method and collaborative study. Journal of AOAC International, 99(5), 1295-1304. https://doi.org/10. 5740/jaoacint.15-0318

Gougeon, L., Da Costa, G., Le Mao, I., Ma, W., Teissedre, P.-L., Guyon, F., \& Richard, T. (2018). Wine analysis and authenticity using $1 \mathrm{H}-\mathrm{NMR}$ metabolomics data: Application to Chinese wines. Food Analytical Methods, 11(12), 3425-3434. https://doi.org/ 10.1007/s12161-018-1310-2

Gougeon, L., da Costa, G., Guyon, F., \& Richard, T. (2019a). 1H NMR metabolomics applied to Bordeaux red wines. Food Chemistry, 301, 125257. https://doi.org/10.1016/j.foodchem.2019.125257

Gougeon, L., da Costa, G., Richard, T., \& Guyon, F. (2019b). Wine authenticity by quantitative $1 \mathrm{H}$ NMR Versus multitechnique 
analysis: A case study. Food Analytical Methods, 12(4), 956-965. https://doi.org/10.1007/s12161-018-01425-Z

Guyon, F., van Leeuwen, C., Gaillard, L., Grand, M., Akoka, S., Remaud, G. S., ... Salagoïty, M. H. (2015). Comparative study of 13C composition in ethanol and bulk dry wine using isotope ratio monitoring by mass spectrometry and by nuclear magnetic resonance as an indicator of vine water status. Analytical and Bioanalytical Chemistry, 407(30), 9053-9060. https://doi.org/10.1007/ s00216-015-9072-9

Hanson, B. A. (n.d.). An introduction to ChemoSpec. Retrieved from ftp://155.232.191.200/cran/web/packages/ChemoSpec/vignettes/ ChemoSpec.pdf

Hanson, B. A. (2020). FOSS for spectroscopy. Retrieved from https: //bryanhanson.github.io/FOSS4Spectroscopy/

Hao, J., Astle, W., De Iorio, M., \& Ebbels, T. M. D. (2012). BATMANan $\mathrm{R}$ package for the automated quantification of metabolites from nuclear magnetic resonance spectra using a Bayesian model. Bioinformatics, 28(15), 2088-2090. https://doi.org/10.1093/ bioinformatics/bts308

Hao, J., Liebeke, M., Astle, W., De Iorio, M., Bundy, J. G., \& Ebbels, T. M. D. (2014). Bayesian deconvolution and quantification of metabolites in complex 1D NMR spectra using BATMAN. Nature Protocols, 9(6), 1416-1427. https://doi.org/10.1038/nprot.2014.090

de Harrington, P. B. (2018). Multiple versus single set validation of multivariate models to avoid mistakes. Critical Reviews in Analytical Chemistry, 48(1), 33-46. https://doi.org/10.1080/10408347.2017. 1361314

Hedjazi, L., Gauguier, D., Zalloua, P. A., Nicholson, J. K., Dumas, M. E., \& Cazier, J. B. (2015). mQTL.NMR: An integrated suite for genetic mapping of quantitative variations of $1 \mathrm{H}$ NMR-Based metabolic profiles. Analytical Chemistry, 87(8), 4377-4384. https: //doi.org/10.1021/acs.analchem.5b00145

Herbert-Pucheta, J. E., Mejía-Fonseca, I., Zepeda-Vallejo, L. G., Milmo-Brittingham, D., \& Maya, G. P. (2019). The "Wine-T1" NMR experiment for novel wine-metabolome fingerprinting with nuclear-spin relaxation. BIO Web of Conferences, 12, 02029. https: //doi.org/10.1051/bioconf/20191202029

Hofmann, M. (2015). A method for wine analysis and related apparatus. Patent DE:102014203815:A1.

Holden, N. E., Coplen, T. B., \& Böhlke, J. K. (2018). IUPAC periodic table of the elements and isotopes (IPTEI) for the education community (IUPAC technical report). Pure and Applied Chemistry, 90(12), 1833-2092. https://doi.org/10.1515/pac-2015-0703

Holmberg, L. (2010). Wine fraud. International Journal of Wine Research, 2010(2), 105-113, https://doi.org/10.2147/IJWR.S14102

Hu, B., Cao, Y., Zhu, J., Xu, W., \& Wu, W. (2019). Analysis of metabolites in chardonnay dry white wine with various inactive yeasts by $1 \mathrm{H}$ NMR spectroscopy combined with pattern recognition analysis. AMB Express, 9(1), 140. https://doi.org/10.1186/s13568-0190861-y

Hu, B., Yue, Y., Zhu, Y., Wen, W., Zhang, F., \& Hardie, J. W. (2015). Proton nuclear magnetic resonance-spectroscopic discrimination of wines reflects genetic homology of several different grape (V. vinifera L.) cultivars. PloS One, 10(12), e0142840. https://doi.org/ 10.1371/journal.pone. 0142840

Humpfer, E., Schaefer, H., Schuetz, B., Moertter, M., Spraul, M., \& Rinke, P. (2009). NMR-based multi parametric quality control of fruit juices. In M. Guðjónsdóttir, P. S. Belton, G. A. Webb (Eds.), Magnetic resonance in food science (pp. 97-104).
Cambridge, United Kingdom: RSC Publishing. https://doi.org/10. 1039/9781847559494-00097

International Organization of Vine and Wine. (2017). 2017 world vitiviniculture situation. OIV statistical report on world vitiviniculture. Retrieved from http://www.oiv.int/public/medias/5479/ oiv-en-bilan-2017.pdf

International Organization of Vine and Wine. (2019a). 2019 Statistical report on world vitiviniculture. Retrieved from http://oiv.int/public/medias/6782/oiv-2019-statistical-report-onworld-vitiviniculture.pdf

International Organization of Vine and Wine. (2019b). State of vitiviniculture. Retrieved from http://www.oiv.int/en/technicalstandards-and-documents/statistical-analysis/state-ofvitiviniculture

International Organization Of Vine And Wine. (2019c). Determination of the deuterium distribution in ethanol derived from fermentation of grape musts, concentrated grape musts, grape sugar (rectified concentrated grape musts) and wines by application of nuclear magnetic resonance. (2019). Compendium of international methods of analysis of wines and musts (2 vol.) (Vol. 1, pp. OIV - MA - AS311-05). Retrieved from http://www.oiv.int/en/technical-standards-anddocuments/methods-of-analysis/compendium-of-internationalmethods-of-analysis-of-wines-and-musts-2-vol

Jacob, D., Deborde, C., Lefebvre, M., Maucourt, M., \& Moing, A. (2017). NMRProcFlow: A graphical and interactive tool dedicated to 1D spectra processing for NMR-based metabolomics. Metabolomics: Official Journal of the Metabolomic Society, 13(4), 36. https://doi.org/10.1007/s11306-017-1178-y

Jeandet, P., Heinzmann, S. S., Roullier-Gall, C., Cilindre, C., Aron, A., Deville, M. A., ... Schmitt-Kopplin, P. (2015). Chemical messages in 170-year-old champagne bottles from the Baltic Sea: Revealing tastes from the past. Proceedings of the National Academy of Sciences of the United States of America, 112(19), 5893-5898. https: //doi.org/10.1073/pnas.1500783112

Jezequel, T., Joubert, V., Giraudeau, P., Remaud, G. S., \& Akoka, S. (2017). The new face of isotopic NMR at natural abundance. Magnetic Resonance in Chemistry: MRC, 55(2), 77-90. https://doi.org/ 10.1002/mrc.4548

Kessler, P., \& Godejohann, M. (2018). Identification of tentative marker in Corvina and Primitivo wines with CMC-se. Magnetic Resonance in Chemistry: MRC, 56(6), 480-492. https://doi.org/10. 1002/mrc.4712

Kioroglou, D., Mas, A., \& Portillo, M. C. (2020). Qualitative factorbased comparison of NMR, targeted and untargeted GC-MS and LC-MS on the metabolomic profiles of rioja and priorat red wines. Foods, 9, 1381. https://doi.org/10.3390/foods9101381

Koda, M., Furihata, K., Wei, F., Miyakawa, T., \& Tanokura, M. (2012). NMR-Based metabolic profiling of rice wines by F2-selective total correlation spectra. Journal of Agricultural and Food Chemistry, 60(19), 4818-4825. https://doi.org/10.1021/jf3008647

Kontogianni, V. G., Tsiafoulis, C. G., Roussis, I. G., \& Gerothanassis, I. P. (2017). Selective 1D TOCSY NMR method for the determination of glutathione in white wine. Analytical Methods, 9(30), 44644470. https://doi.org/10.1039/C7AY01463E

Kosir, I. J., \& Kidric, J. (2001). Identification of amino acids in wines by one- and two-dimensional nuclear magnetic resonance spectroscopy. Journal of Agricultural and Food Chemistry, 49(1), 50-56. https://doi.org/10.1021/jf0008137 
Krastev, T. (2007). spectrino software: Spectra visualization and preparation for R. Journal of Statistical Software, 18(10), 116.Retrieved from https://doi.org/10.18637/jss.v018.i10

Lee, J. E., Hwang, G. S., van den Berg, F., Lee, C. H., \& Hong, Y. S. (2009). Evidence of vintage effects on grape wines using $1 \mathrm{H}$ NMRbased metabolomic study. Analytica Chimica Acta, 648(1), 71-76. https://doi.org/10.1016/j.aca.2009.06.039

Lefort, G., Liaubet, L., Canlet, C., Tardivel, P., Père, M.-C., Quesnel, H., ... Servien, R. (2019). ASICS: An R package for a whole analysis workflow of 1D 1H NMR spectra. Bioinformatics, 35(21), 43564363. https://doi.org/10.1093/bioinformatics/btz248

Lewis, I. A., Schommer, S. C., \& Markley, J. L. (2009). rNMR: Open source software for identifying and quantifying metabolites in NMR spectra. Magnetic Resonance in Chemistry: MRC, 47(Suppl 1), S123-S126. https://doi.org/10.1002/mrc.2526

Link, M., Spraul, M., Schaefer, H., Fang, F., \& Schuetz, B. (2013). Novel NMR-technology to assess food quality and safety. International Journal of Nutrition and Food Engineering, 7(10), 960-963. https://doi.org/10.5281/zenodo.1088128

López-Rituerto, E., Cabredo, S., Lopez, M., Avenoza, A., Busto, J. H., \& Peregrina, J. M. (2009). A thorough study on the use of quantitative $1 \mathrm{H}$ NMR in Rioja red wine fermentation processes. Journal of Agricultural and Food Chemistry, 57(6), 2112-2118. https: //doi.org/10.1021/jf803245r

Ma, W., Waffo-Téguo, P., Jourdes, M., Li, H., \& Teissedre, P.-L. (2018). First evidence of epicatechin vanillate in grape seed and red wine. Food Chemistry, 259, 304-310. https://doi.org/10.1016/j.foodchem. 2018.03.134

Madrid-Gambin, F., Oller-Moreno, S., Fernandez, L., Bartova, S., Giner, M. P., Joyce, C., ... Marco, S. (2020). AlpsNMR: An R package for signal processing of fully untargeted NMR-based metabolomics. Bioinformatics, 36(9), 2943-2945. https://doi.org/ 10.1093/bioinformatics/btaa022

Magdas, D. A., Pirnau, A., Feher, I., Guyon, F., \& Cozar, B. I. (2019). Alternative approach of applying $1 \mathrm{H}$ NMR in conjunction with chemometrics for wine classification. LWT, 109, 422-428. https: //doi.org/10.1016/j.lwt.2019.04.054

Martin, G. J., Guillou, C., Martin, M. L., Cabanis, M. T., Tep, Y., \& Aerny, J. (1988). Natural factors of isotope fractionation and the characterization of wines. Journal of Agricultural and Food Chemistry, 36(2), 316-322. https://doi.org/10.1021/jf00080a019

Martin, G. J., \& Martin, M. L. (1981). Deuterium labelling at the natural abundance level as studied by high field quantitative $2 \mathrm{H}$ NMR. Tetrahedron Letters, 22(36), 3525-3528. https://doi.org/10. 1016/S0040-4039(01)81948-1

Martin, G. J., Martin, M. L., Mabon, F., \& Michon, M. J. (1982). Identification of the origin of natural alcohols by natural abundance hydrogen-2 nuclear magnetic resonance. Analytical Chemistry, 54(13), 2380-2382. https://doi.org/10.1021/ac00250a057

Martin, G. J., Martin, M. L., Mabon, F., \& Michon, M. J. (1983). A new method for the identification of the origin of ethanols in grain and fruit spirits: High-field quantitative deuterium nuclear magnetic resonance at the natural abundance level. Journal of Agricultural and Food Chemistry, 31(2), 311-315.Retrieved from https: //pubs.acs.org/doi/pdf/10.1021/jf00116a032

Martin, M., Legat, B., Leenders, J., Vanwinsberghe, J., Rousseau, R., Boulanger, B., ... Govaerts, B. (2018). PepsNMR for $1 \mathrm{H}$ NMR metabolomic data pre-processing. Analytica Chimica Acta, 1019, 1-13. https://doi.org/10.1016/j.aca.2018.02.067
Mayo, D. W., Pike, R. M., \& Hinkle, R. J. (1988). Spinning band fractionating column. US Patent (No. 4770746).

Mazzei, P., Celano, G., Palese, A. M., Lardo, E., Drosos, M., \& Piccolo, A. (2019). HRMAS-NMR metabolomics of Aglianicone grapes pulp to evaluate terroir and vintage effects, and, as assessed by the electromagnetic induction (EMI) technique, spatial variability of vineyard soils. Food Chemistry, 283, 215-223. https://doi.org/ 10.1016/j.foodchem.2019.01.012

Medina, B., Salagoity, M. H., Guyon, F., Gaye, J., Hubert, P., \& Guillaume, F. (2013). Using new analytical approaches to verify the origin of wine. In P. Brereton (Ed.), New analytical approaches for verifying the origin of food (pp. 149-188). Elsevier. https://doi.org/10. 1533/9780857097590.3.149

Meier-Augenstein, W. (1999). Applied gas chromatography coupled to isotope ratio mass spectrometry. Journal of Chromatography. A, 842(1-2), 351-371. https://doi.org/10.1016/s0021-9673(98) 01057-7

Meija, J., Coplen, T. B., Berglund, M., Brand, W. A., De Bièvre, P., Gröning, M., ... Prohaska, T. (2016). Isotopic compositions of the elements 2013 (IUPAC technical report). Pure and Applied Chemistry, 88(3), 293-306. https://doi.org/10.1515/pac-2015-0503

Mendez, K. M., Pritchard, L., Reinke, S. N., \& Broadhurst, D. I. (2019). Toward collaborative open data science in metabolomics using Jupyter Notebooks and cloud computing. Metabolomics: Official Journal of the Metabolomic Society, 15(10), 125. https://doi.org/10. 1007/s11306-019-1588-0

Minoja, A. P., \& Napoli, C. (2014). NMR screening in the quality control of food and nutraceuticals. Food Research International, 63, 126-131. https://doi.org/10.1016/j.foodres.2014.04.056

Monakhova, Y. B., Godelmann, R., Hermann, A., Kuballa, T., Cannet, C., Schäfer, H., ... Rutledge, D. N. (2014). Synergistic effect of the simultaneous chemometric analysis of $1 \mathrm{H}$ NMR spectroscopic and stable isotope (SNIF-NMR, 18O, 13C) data: Application to wine analysis. Analytica Chimica Acta, 833, 29-39. https: //doi.org/10.1016/j.aca.2014.05.005

Monakhova, Y. B., Schäfer, H., Humpfer, E., Spraul, M., Kuballa, T., \& Lachenmeier, D. W. (2011). Application of automated eightfold suppression of water and ethanol signals in $1 \mathrm{H}$ NMR to provide sensitivity for analyzing alcoholic beverages. Magnetic Resonance in Chemistry: MRC, 49(11), 734-739. https://doi.org/10.1002/mrc. 2823

Monakhova, Y. B., Schütz, B., Schäfer, H., Spraul, M., Kuballa, T., Hahn, H., \& Lachenmeier, D. W. (2014). Validation studies for multicomponent quantitative NMR analysis: The example of apple fruit juice. Accreditation and Quality Assurance, 19(1), 17-29. https: //doi.org/10.1007/s00769-013-1026-3

Montet, D., \& Ray, R. C. (Eds.). (2017). Food traceability and authenticity: Analytical techniques. CRC Press.

Moore, J. C., Spink, J., \& Lipp, M. (2012). Development and application of a database of food ingredient fraud and economically motivated adulteration from 1980 to 2010. Journal of Food Science, 77(4), R118-R126. https://doi.org/10.1111/j.1750-3841.2012.02657.x

Moreno-Arribas, M. V., \& Polo, M. C. (Eds.). (2009). Wine chemistry and biochemistry. Springer. https://doi.org/10.1007/978-0387-74118-5

Muhammad, A., \& Country, A. M. (2019). In vino 'no' veritas: Impacts of fraud on wine imports in China. The Australian Journal of Agricultural and Resource Economics, 63(4), 742-758. https://doi.org/ 10.1111/1467-8489.12333 
Nilsson, M., Duarte, I. F., Almeida, C., Delgadillo, I., Goodfellow, B. J., Gil, A. M., \& Morris, G. A. (2004). High-resolution NMR and diffusion-ordered spectroscopy of port wine. Journal of Agricultural and Food Chemistry, 52(12), 3736-3743. https://doi.org/10. 1021/jf049797u

Pan, Z., \& Raftery, D. (2007). Comparing and combining NMR spectroscopy and mass spectrometry in metabolomics. Analytical and Bioanalytical Chemistry, 387(2), 525-527. https://doi.org/10.1007/ s00216-006-0687-8

Pauli, G. F., Gödecke, T., Jaki, B. U., \& Lankin, D. C. (2012). Quantitative 1 H NMR. Development and potential of an analytical method: An update. Journal of Natural Products, 75(4), 834-851. https://doi. org/10.1021/np200993k

Pauli, G. F., Jaki, B. U., \& Lankin, D. C. (2005). Quantitative $1 \mathrm{H}$ NMR: Development and potential of a method for natural products analysis. Journal of Natural Products, 68(1), 133-149. https: //doi.org/10.1021/np0497301

Pereira, G. E., Gaudillère, J.-P., Van Leeuwen, C., Hilbert, G., Maucourt, M., Deborde, C., ... Rolin, D. (2007). 1H-NMR metabolic profiling of wines from three cultivars, three soil types and two contrasting vintages. OENO One, 41(2), 103. https://doi.org/10. 20870/oeno-one.2007.41.2.850

Picone, G., Savorani, F., Trimigno, A., Mezzetti, B., Capozzi, F., \& Engelsen, S. B. (2016). Metabolic changes of genetically engineered grapes (Vitis vinifera L.) studied by $1 \mathrm{H}-\mathrm{NMR}$, metabolite heatmaps and iPLS. Metabolomics: Official Journal of the Metabolomic Society, 12(10), 150. https://doi.org/10.1007/s11306-016-1095-5

Picone, G., Trimigno, A., Tessarin, P., Donnini, S., Rombolà, A. D., \& Capozzi, F. (2016). 1H NMR foodomics reveals that the biodynamic and the organic cultivation managements produce different grape berries (Vitis vinifera L. cv. Sangiovese). Food Chemistry, 213, 187195. https://doi.org/10.1016/j.foodchem.2016.06.077

Pinto, J., Oliveira, A. S., Azevedo, J., De Freitas, V., Lopes, P., Roseira, I., ... de Pinho, P. G. (2018). Assessment of oxidation compounds in oaked Chardonnay wines: A GC-MS and 1 H NMR metabolomics approach. Food Chemistry, 257, 120-127. https://doi.org/10.1016/j. foodchem.2018.02.156

Pinto, J., Oliveira, A. S., Lopes, P., Roseira, I., Cabral, M., Bastos, M., ... Guedes de Pinho, P. (2019). Characterization of chemical compounds susceptible to be extracted from cork by the wine using GC-MS and 1H NMR metabolomic approaches. Food Chemistry, 271, 639-649. https://doi.org/10.1016/j.foodchem.2018.07.222

Pinu, F. (2018). Grape and wine metabolomics to develop new insights using untargeted and targeted approaches. Fermentation, 4(4), 92. https://doi.org/10.3390/fermentation4040092

Puchades-Carrasco, L., Palomino-Schätzlein, M., Pérez-Rambla, C., \& Pineda-Lucena, A. (2016). Bioinformatics tools for the analysis of NMR metabolomics studies focused on the identification of clinically relevant biomarkers. Briefings in Bioinformatics, 17(3), 541-552. https://doi.org/10.1093/bib/bbv077

R Core Team. (2020). R: A language and environment for statistical computing. Vienna, Austria: R Foundation for Statistical Computing. Retrieved from https://cran.r-project.org/doc/manuals/ fullrefman.pdf

Radovanović, B. C., Radovanović, A. N., \& Arsić, B. B. (2018). A new chemometric approach to the fingerprinting analysis of grapes and wines based on phenolic profile and antimicrobial activities. In J. D. Perez (Ed.), A closer look at grapes, wines and winemaking (pp. 1-42). Nova Science Publishers, Inc.
Ralli, E., Amargianitaki, M., Manolopoulou, E., Misiak, M., Markakis, G., Tachtalidou, S., ... Spyros, A. (2018). NMR Spectroscopy protocols for food metabolomics applications. Methods in Molecular Biology, 1738, 203-211. https://doi.org/10.1007/978-14939-7643-0_14

Rapp, A., Markowetz, A., Spraul, M., \& Humpfer, E. (1988). Anwendung der 13C-NMR-Spektroskopie in der Weinanalytik. Fresenius Zeitschrift Fur Analytische Chemie, 330, 462-463. https://doi.org/ 10.1007/BF00469370

Remaud, G. S., Silvestre, V., \& Akoka, S. (2005). Traceability in quantitative NMR using an electronic signal as working standard. Accreditation and Quality Assurance, 10(8), 415-420. https://doi. org/10.1007/s00769-005-0044-1

Ricci, A., Parpiniello, G., Laghi, L., Lambri, M., \& Versari, A. (2013). Application of infrared spectroscopy to grape and wine analysis. In D. Cozzolino (Ed.), Infrared spectroscopy: Theory, developments and applications (pp. 17-42). Nova Science.

Riedl, J., Esslinger, S., \& Fauhl-Hassek, C. (2015). Review of validation and reporting of non-targeted fingerprinting approaches for food authentication. Analytica Chimica Acta, 885, 17-32. https: //doi.org/10.1016/j.aca.2015.06.003

Robinson, J., \& Harding, J. (2015). The Oxford companion to wine. Oxford University Press.

Rochfort, S., Ezernieks, V., Bastian, S. E. P., \& Downey, M. O. (2010). Sensory attributes of wine influenced by variety and berry shading discriminated by NMR metabolomics. Food Chemistry, 121(4), 1296-1304. https://doi.org/10.1016/j.foodchem.2010.01.067

Rodriguez-Martinez, A., Ayala, R., Posma, J. M., Harvey, N., Jiménez, B., Sonomura, K., ... Dumas, M. E. (2019). pJRES Binning Algorithm (JBA): A new method to facilitate the recovery of metabolic information from pJRES 1H NMR spectra. Bioinformatics, 35(11), 1916-1922. https://doi.org/10.1093/bioinformatics/bty837

Rodriguez-Martinez, A., Posma, J. M., Ayala, R., Neves, A. L., Anwar, M., Petretto, E., ... Dumas, M.-E. (2018). MWASTools: An R/bioconductor package for metabolome-wide association studies. Bioinformatics, 34(5), 890-892. https://doi.org/10.1093/ bioinformatics/btx477

Sangster, T., Major, H., Plumb, R., Wilson, A. J., \& Wilson, I. D. (2006). A pragmatic and readily implemented quality control strategy for HPLC-MS and GC-MS-based metabonomic analysis. The Analyst, 131(10), 1075-1078. https://doi.org/10.1039/ b604498k

Savorani, F., Tomasi, G., \& Engelsen, S. B. (2010). icoshift: A versatile tool for the rapid alignment of 1D NMR spectra. Journal of Magnetic Resonance, 202(2), 190-202. https://doi.org/10.1016/j. jmr.2009.11.012

Schmitt, M., Broschart, S., Patz, C. D., Rauhut, D., Friedel, M., \& Häge, D. (2019). Application of yeast with reduced alcohol yield for sparkling wine production. BIO Web of Conferences, 12, 02021. https://doi.org/10.1051/bioconf/20191202021

Serra-Cayuela, A., Castellari, M., Bosch-Fusté, J., Riu-Aumatell, M., Buxaderas, S., \& López-Tamames, E. (2013). Identification of 5hydroxymethyl-2-furfural (5-HMF) in Cava sparkling wines by LCDAD-MS/MS and NMR spectrometry. Food Chemistry, 141, 33733380. https://doi.org/10.1016/j.foodchem.2013.05.158

Shen, A. (2018). 'Being affluent, one drinks wine': Wine counterfeiting in Mainland China. International Journal for Crime, Justice and Social Democracy, 7(4), 16-32. https://doi.org/10.5204/ijcjsd. v7i4.1086 
Sindt, L., Gammacurta, M., Waffo-Teguo, P., Dubourdieu, D., \& Marchal, A. (2016). Taste-Guided Isolation of Bitter Lignans from Quercus petraea and Their Identification in Wine. Journal of Natural Products, 79(10), 2432-2438. https://doi.org/10.1021/acs. jnatprod.6b00142

Smolinska, A., Blanchet, L., Buydens, L. M. C., \& Wijmenga, S. S. (2012). NMR and pattern recognition methods in metabolomics: From data acquisition to biomarker discovery: A review. In Analytica Chimica Acta, Vol. 750, 82-97). https://doi.org/10.1016/j.aca. 2012.05.049

Sobieski, D. N., Mulvihill, G., Broz, J. S., \& Augustine, M. P. (2006). Towards rapid throughput NMR studies of full wine bottles. Solid State Nuclear Magnetic Resonance, 29(1-3), 191-198. https://doi. org/10.1016/j.ssnmr.2005.08.014

Sobolev, A. P., Thomas, F., Donarski, J., Ingallina, C., Circi, S., Cesare Marincola, F., ... Mannina, L. (2019). Use of NMR applications to tackle future food fraud issues. Trends in Food Science \& Technology, 91, 347-353. https://doi.org/10.1016/j.tifs.2019.07.035

Son, H.-S., Kim, K. M., van den Berg, F., Hwang, G.-S., Park, W.-M., Lee, C.-H., \& Hong, Y.-S. (2008). 1H nuclear magnetic resonancebased metabolomic characterization of wines by grape varieties and production areas. Journal of Agricultural and Food Chemistry, 56(17), 8007-8016. https://doi.org/10.1021/jf801424u

Spraul, M., Humpfer, E., Schäfer, H., Schütz, B., Mörtter, M., \& Rinke, P. (2008). NMR-based mixture analysis on the example of fruit juice quality control using statistics and quantification. In U. Holzgrabe, I. Wawer, \& B. Diehl (Eds.), NMR spectroscopy in pharmaceutical analysis (pp. 317-339). Elsevier B.V. https://doi.org/10. 1016/b978-0-444-53173-5.00013-5

Spraul, M., Link, M., Schaefer, H., Fang, F., \& Schuetz, B. (2015). Wine analysis to check quality and authenticity by fully-automated $1 \mathrm{H}$ NMR. BIO Web of Conferences, 5, 02022. https://doi.org/10.1051/ bioconf/20150502022

Spraul, M., Schütz, B., Humpfer, E., Mörtter, M., Schäfer, H., Koswig, S., \& Rinke, P. (2009). Mixture analysis by NMR as applied to fruit juice quality control. Magnetic Resonance in Chemistry: MRC, 47(Suppl 1), S130-S137. https://doi.org/10.1002/mrc.2528

Spraul, M., Schütz, B., Rinke, P., Koswig, S., Humpfer, E., Schäfer, H., ... Minoja, A. (2009). NMR-Based multi parametric quality control of fruit juices: SGF profiling. Nutrients, 1(2), 148-155. https://doi. org/10.3390/nu1020148

Spyros, A., \& Dais, P. (2012). Wine and Beverages. In P. S. Belton (Ed.) NMR Spectroscopy in food analysis (pp. 202-240). Cambridge, United Kingdom: RSC Publishing. https://doi.org/10.1039/ 9781849735339-00202

Tardivel, P. J. C., Canlet, C., Lefort, G., Tremblay-Franco, M., Debrauwer, L., Concordet, D., \& Servien, R. (2017). ASICS: An automatic method for identification and quantification of metabolites in complex 1D 1H NMR spectra. Metabolomics: Official Journal of the Metabolomic Society, 13(10), 109. https://doi.org/10.1007/ s11306-017-1244-5

Thomas, F., Randet, C., Gilbert, A., Silvestre, V., Jamin, E., Akoka, S., ... Guillou, C. (2010). Improved characterization of the botanical origin of sugar by carbon-13 SNIF-NMR applied to ethanol. Journal of Agricultural and Food Chemistry, 58(22), 11580-11585. https://doi.org/10.1021/jf102983v
Ulaszewska, M. M., Weinert, C. H., Trimigno, A., Portmann, R., Andres Lacueva, C., Badertscher, R., ... Vergères, G. (2019). Nutrimetabolomics: An integrative action for metabolomic analyses in human nutritional studies. Molecular Nutrition \& Food Research, 63(1), e1800384. https://doi.org/10.1002/mnfr. 201800384

United States Pharmacopeia (2019). USP guidance on developing and validating non-targeted methods for adulteration detection. Food Chemicals Codex, 11th Edition, Third Supplement.

Vitrac, X., Bornet, A., Vanderlinde, R., Valls, J., Richard, T., Delaunay, J. C., ... Teissédre, P. L. (2005). Determination of Stilbenes $(\delta$-viniferin, trans-astringin, trans-piceid, cis- and transresveratrol, $\varepsilon$-viniferin) in Brazilian Wines. Journal of Agricultural and Food Chemistry, 53(14), 5664-5669. https://doi.org/10.1021/ jf050122g

Wang, K., Barding, G. A., \& Larive, C. K. (2015). Peak alignment of one-dimensional NMR spectra by means of an intensity fluctuation frequency difference (IFFD) segment-wise algorithm. Analytical Methods, 7(22), 9673-9682. https://doi.org/10. 1039/C5AY01079A

Waterhouse, A. L., Sacks, G. L., \& Jeffery, D. W. (2016). Understanding wine chemistry. John Wiley \& Sons.

Weekley, A. J., Bruins, P., \& Augustine, M. P. (2002). Nondestructive method of determining acetic acid spoilage in an unopened bottle of wine. American Journal of Enology and Viticulture, 53(4), 318-321.Retrieved from https://www.ajevonline.org/content/ $53 / 4 / 318$

Weekley, A. J., Bruins, P., Sisto, M., \& Augustine, M. P. (2003). Using NMR to study full intact wine bottles. Journal of Magnetic Resonance, 161(1), 91-98. https://doi.org/10.1016/s1090-7807(02) 00177-5

Westad, F., \& Marini, F. (2015). Validation of chemometric modelsA tutorial. Analytica Chimica Acta, 893, 14-24. https://doi.org/10. 1016/j.aca.2015.06.056

Wine and Spirit Trade Association (2015). Wine and spirits in the UK: A socially responsible industry. Retrieved from https://www.wsta. co.uk/wp-content/uploads/2019/02/CSRBooklet2015.pdf

Worley, B., \& Powers, R. (2014). MVAPACK: A complete data handling package for NMR Metabolomics. ACS Chemical Biology, 9(5), 1138-1144. https://doi.org/10.1021/cb4008937

Ye, Q., Wang, H., \& Xu, J. (2015). Application of NMR spectroscopy for the characterization of dietary polyphenols. In A. ur-Rahman \& M. I. Choudhary (Eds.), Applications of NMR spectroscopy (Vol. 3, pp, 37-77). Bentham Science Publishers. https://doi.org/10.1016/B9781-68108-063-5.50002-3

Zerbe, O., \& Jurt, S. (2013). Applied NMR spectroscopy for chemists and life scientists. John Wiley \& Sons.

Zerbib, M., Mazauric, J.-P., Meudec, E., Le Guernevé, C., Lepak, A., Nidetzky, B., ... Saucier, C. (2018). New flavanol O-glycosides in grape and wine. Food Chemistry, 266, 441-448. https://doi.org/10. 1016/j.foodchem.2018.06.019

Zhang, B. L., Trierweiler, M., Jouitteau, C., \& Martin, G. J. (1999). Consistency of NMR and mass spectrometry determinations of natural-abundance site-specific carbon isotope ratios. The case of glycerol. Analytical Chemistry, 71(13), 2301-2306. https://doi.org/ 10.1021/ac9812375 
Zhu, J., Hu, B., Lu, J., \& Xu, S. (2018). Analysis of metabolites in Cabernet Sauvignon and Shiraz dry red wines from Shanxi by $1 \mathrm{H}$ NMR spectroscopy combined with pattern recognition analysis. Open Chemistry, 16(1), 446-452. https://doi.org/10.1515/chem2018-0052

Zoecklein, B., Fugelsang, K. C., Gump, B. H., \& Nury, F. S. (1999). Wine analysis and production. Springer Science \& Business Media.
How to cite this article: Solovyev PA, Fauhl-Hassek C, Riedl J, et al. NMR spectroscopy in wine authentication: an official control perspective. Compr Rev Food Sci Food Saf. 2021;20:2040-2062. https://doi.org/10.1111/1541-4337.12700 